\title{
The MetNet vehicle: a lander to deploy environmental stations for local and global investigations of Mars
}

\author{
Ari-Matti Harri ${ }^{1}$, Konstantin Pichkadze ${ }^{2}$, Lev Zeleny ${ }^{3}$, Luis Vazquez ${ }^{5}$, Walter Schmidt ${ }^{1}$, Sergey Alexashkin $^{2}$, \\ Oleg Korablev $^{3}$, Hector Guerrero ${ }^{4}$, Jyri Heilimo ${ }^{1}$, Mikhail Uspensky ${ }^{1}$, Valery Finchenko ${ }^{2}$, Vyacheslav Linkin $^{3}$, \\ Ignacio Arruego ${ }^{4}$, Maria Genzer ${ }^{1}$, Alexander Lipatov ${ }^{3}$, Jouni Polkko ${ }^{1}$, Mark Paton ${ }^{1}$, Hannu Savijärvi ${ }^{8}$, \\ Harri Haukka $^{1}$, Tero Siili ${ }^{1}$, Vladimir Khovanskov ${ }^{2}$, Boris Ostesko $^{2}$, Andrey Poroshin ${ }^{6}$, Marina Diaz-Michelena $^{4}$, \\ Timo Siikonen ${ }^{7}$, Matti Palin ${ }^{7}$, Viktor Vorontsov ${ }^{2}$, Alexander Polyakov ${ }^{2}$, Francisco Valero ${ }^{5}$, Osku Kemppinen ${ }^{1}$, \\ Jussi Leinonen $^{1}$, and Pilar Romero ${ }^{5}$ \\ ${ }^{1}$ Research Division, Finnish Meteorological Institute, Helsinki, Finland \\ ${ }^{2}$ Planetary Systems Department, Lavochkin Association, Moscow, Russia \\ ${ }^{3}$ Planetary Science Laboratory, Russian Space Research Center (IKI), Moscow, Russia \\ ${ }^{4}$ Microelectronics Department, Instituto Nacional de Tecnica Aeroespacial (INTA), Madrid, Spain \\ ${ }^{5}$ Computational Mathematics Dept, Universidad Complutense de Madrid, Madrid, Spain \\ ${ }^{6}$ Dauria Ltd, Moscow, Russia \\ ${ }^{7}$ Finflo Ltd, Espoo, Finland \\ ${ }^{8}$ Dept of Physics, University of Helsinki, Finland
}

Correspondence to: Ari-Matti Harri (ari-matti.harri@ fmi.fi)

Received: 27 June 2016 - Discussion started: 2 August 2016

Revised: 7 December 2016 - Accepted: 10 January 2017 - Published: 24 February 2017

\begin{abstract}
Investigations of global and related local phenomena on Mars such as atmospheric circulation patterns, boundary layer phenomena, water, dust and climatological cycles and investigations of the planetary interior would benefit from simultaneous, distributed in situ measurements. Practically, such an observation network would require low-mass landers, with a high packing density, so a large number of landers could be delivered to Mars with the minimum number of launchers.

The Mars Network Lander (MetNet Lander; MNL), a small semi-hard lander/penetrator design with a payload mass fraction of approximately $17 \%$, has been developed, tested and prototyped. The MNL features an innovative Entry, Descent and Landing System (EDLS) that is based on inflatable structures. The EDLS is capable of decelerating the lander from interplanetary transfer trajectories down to a surface impact speed of $50-70 \mathrm{~m} \mathrm{~s}^{-1}$ with a deceleration of $<500 \mathrm{~g}$ for $<20 \mathrm{~ms}$. The total mass of the prototype design is $\approx 24 \mathrm{~kg}$, with $\approx 4 \mathrm{~kg}$ of mass available for the payload.

The EDLS is designed to orient the penetrator for a vertical impact. As the payload bay will be embedded in the surface
\end{abstract}

materials, the bay's temperature excursions will be much less than if it were fully exposed on the Martian surface, allowing a reduction in the amount of thermal insulation and savings on mass.

The MNL is well suited for delivering meteorological and atmospheric instruments to the Martian surface. The payload concept also enables the use of other environmental instruments. The small size and low mass of a MNL makes it ideally suited for piggy-backing on larger spacecraft. MNLs are designed primarily for use as surface networks but could also be used as pathfinders for high-value landed missions.

\section{Introduction}

Significant progress in several areas of scientific investigation on Mars, such as climate circulation, water cycle, sedimentary cycle and surface-atmosphere interactions, has been made possible with spacecraft observations at Mars (Soffen, 1976; Golombek et al., 1999; Smith et al., 2008). In many investigations significant progress is contingent on good spatial 
coverage at several locations (MESUR study report; Chicarro et al., 1993; Harri et al., 1998; Linkin et al., 1998; Harri et al., $1999,2007)$ with extended temporal and simultaneous coverage, requiring the concurrent operation of several spacecraft. Current orbital and lander observations are restricted in spatial measurements primarily due to the low number of active spacecraft available $(\sim 2)$ for making simultaneous coordinated observations.

The payload mass of the launchers, and their cost, restricts the number of spacecraft and instruments that can be delivered to Mars during each launch window. Among the wide variety of science instruments and payloads relevant to Mars science and exploration some instruments and instrument types are inherently massive or sensitive, requiring relatively large and massive landing systems to enable a soft landing. Up to now large landers with multi-disciplinary and complex payloads have been favoured; Mars Science Laboratory (MSL) is perhaps the ultimate manifestation (Grotzinger et al., 2012; Gómez-Elvira et al., 2014; Taylor et al., 2008).

The use of lightweight landers would enable the delivery of an observations network to Mars possibly in a single launch. Meteorology, climate studies and seismology are areas of investigation that would benefit from a network of observations. A lightweight lander would require low-mass instruments with minimal use of resources such as power and heating, which is a requirement well suited for making atmospheric measurements. Heating requirements can be minimised by burying the bulk of the spacecraft in the regolith and so thermally isolating it from the extremes of the diurnal temperature range on Mars. Burial could be performed using the inertia of the lander as with penetrators. Keeping the lander mass low and packing density high would maximise the number of landers that could be launched towards Mars with a single launcher. This could be enabled by using inflatable aerodynamic decelerators.

This paper describes the MetNet Lander (MNL) concept, a compact and lightweight vehicle designed to deliver a set of instruments to the surface of Mars. The MNL vehicle uses a combination of lightweight inflatable aerodynamic decelerators and a penetrator-like landing system that also gives the correct final operational attitude. MNL will impact the Martian surface at a relatively lower, and hence safer, speed of around $50 \mathrm{~s}^{-1}$ compared to previous high-speed penetrator designs for Mars. For example, the Mars 96 and DS2 penetrators had impact speeds of 80 and $190 \mathrm{~s}^{-1}$, respectively (e.g. see Ball et al., 2009a). Possible uses of the MNL in Mars exploration along with programmatic and science mission aspects are also discussed.

The paper is organised as follows. In the next section previous Mars landers and their Entry, Descent and Landing System (EDLS) are reviewed in Sect. 2.1. MNL development is reviewed in Sect. 2.2. The selected MNL concept and its EDLS design are discussed and described in Sect. 2.3. Section 3 provides a more detailed description of the MNL mechanical and electrical systems. Potential mission types and scientific applications of the MNL design are outlined and discussed in Sect. 4. Future prospects are outlined and recommendations made in Sect. 5 with Precursor missions outlined in Sect. 5.1.

\section{Background}

\subsection{Brief overview of Mars lander technologies}

The survivability of spacecraft during landing will depend largely on the spacecraft being able to absorb the impact energy without damaging its payload and critical systems. Landers can be divided into three categories with the division of these categories being defined by the landing speed, which is an indicator of the kinetic energy required to be dissipated by the spacecraft's landing system.

A soft lander typically touches down on the surface at a speed of around $1 \mathrm{~m} \mathrm{~s}^{-1}$ using a rocket propulsion system that is initiated at subsonic speeds to control and reduce the speed for a soft touchdown. The advantage of using a propulsion system is that manoeuvres like hazard avoidance, and pinpoint landings are possible. Examples of soft Mars landers are the Viking, Phoenix and MSL (Soffen and Snyder, 1976; Soffen, 1976; Guinn et al., 2008; Grotzinger et al., 2012) landers. Soft landing technology is required for large payloads, heavy payloads and payloads with components sensitive to high mechanical loads.

A hard lander, such as high-speed penetrators, typically impacts the surface at speeds of around $100 \mathrm{~m} \mathrm{~s}^{-1}$ and experiences high decelerations (up to $10^{4} \mathrm{~m} \mathrm{~s}^{-2}$ ) over short time periods during the penetration of the subsurface strata. The use of high-speed penetrators for planetary science were first studied in the USA during the 1970s. The Soviet Union seemed to have initiated its studies in the 1980s (Ball et al., 2009, Chapter 19). In Europe the MarsNet mission (Chicarro et al., 1993) was the first study of a penetrator/hard lander system in the early 1990s.

Penetrators for a variety of solar system destinations have progressed to the concept stage although only two designs have actually been launched (Lorenz, 2011). These are the Russian Mars-96 penetrator (Surkov and Kremnev, 1998) and USA's Deep Space 2 Mars Microprobe (Smrekar et al., 1999). Each mission included two penetrators riding piggyback on a carrier spacecraft. None of these penetrators were successful: the Mars-96 mission failed to reach Earth's escape trajectory and the DS-2 probes' fate after deployment from the Mars Polar Lander is not known. Hard landers provide a platform to take robust science payloads to a planetary surface with a high mass efficiency. This is because the more gently a vehicle lands the more mass is needed for the EDLS to decelerate the vehicle's velocity before the touchdown on the surface.

Semi-hard landers are vehicles that impact the surface at speeds, and experience subsequent decelerations, that are be- 
Table 1. The studied MNL EDLS concept candidates. In each concept the entry and descent phase braking devices are jettisoned to reduce decelerated mass. The concept A1 is as Mars-96 small stations (Linkin et al., 1998) and similar to the selected concept as the Mars-96 penetrators (Surkov and Kremnev, 1998), which used a rigid heat shield. The column title "Entry" refers to the hypersonic and supersonic portion of the flight. "Descent" refers to the subsonic portion of the flight. A "tension cone" refers to a type of inflatable decelerator shaped so as to contain tensile stresses; e.g. see Clark et al. (2009) for more information.

\begin{tabular}{lllll}
\hline Concept & Entry & Descent & Landing & Station type \\
\hline A1 & rigid shell & parachute & airbags & lander \\
A2 & rigid shell & tension cone & airbags & lander \\
B1 & rigid shell & tension cone & internal shock absorber & penetrator \\
B2 & rigid shell & inflatable torus & same as descent & lander \\
B3 & inflatable & attached ballute & internal shock absorber & penetrator \\
Selected & inflatable & tension cone & internal shock absorber & penetrator \\
\hline
\end{tabular}

tween those of a soft lander and a hard lander. Such landers will experience a moderate deceleration of a few hundreds of gees over the time of some tens of milliseconds. Typically low-mass Martian semi-hard landers have thus far used a combination of heat shield, parachutes and airbags (e.g. see Harri et al., 1999, and Linkin et al., 1998) for entry, descent and landing. Heavier semi-hard landers, e.g. Golombek et al. (1999), have used additional retrorockets at the end of the descent phase to decelerate down to the required impact speed. Semi-hard landers provide a practical solution for deploying planetary surface payloads that include robust geophysical instruments and are especially suited for deploying lightweight sensor systems needed to perform atmospheric science experiments.

\subsection{MetNet Lander development history and background}

The work on a semi-hard lander design for the MNL started in August 2000. Five different EDLS concepts (Table 1 and Fig. 1) were initially defined as candidates to be studied. The development of the MNL design was performed over a 7-year period from 2001 to 2008 by a team comprising of FMI, the LA and the Russian Space Research Institute IKI. The Spanish INTA joined the team in 2008. The MNL development work was funded and led by FMI. The MNL concept and key probe technologies were developed and the critical subsystems were qualified to meet the Martian environmental and functional conditions during the years 2002-2005. Development of the required system instrumentation and prototype science payloads to facilitate testing was carried out in 2004-2008.

In the initial phase of the development five different EDLS concepts were assessed from the viewpoint of finding an optimal solution for deployment of small payloads onto the Martian surface. One concept was a traditional, parachute-based approach and the remaining four utilised inflatable structures in various ways.

Comparative analysis between the five concepts, underlining and emphasising reliability, payload fraction and com- plexity of test programme, was carried out. The concepts were categorised into two categories. Category A contained those landers using airbags for landing and category B contained those landers using other impact shock attenuation mechanisms for landing. These categories contained a range of variants as shown in Fig. 1 whose EDLS elements are listed in Table 1. Variants A1 and B3 were selected for additional, more detailed study. This study resulted in the formation of lander concepts known as concept A and concept B. Concept A was essential variant A1, based on the Mars 96 small station, which employed a rigid heat shield, parachutes and airbags. Concept B was a new formulation of the EDLS that employed an inflatable heat shield, tension cone and penetrator to deliver the lander to the surface. Our comparative reliability analysis showed that concept B was significantly more reliable than concept A. This was due to, amongst other things, the lower amount of pyrotechnical devices required by the concept B. Penetration into the Martian regolith results in the vehicle experiencing reduced diurnal temperature variations. This could help reduce the thermal protection requirement, reducing mass, and in addition permit a wider range of qualified components for use in the vehicle. The current MNL design was chosen as it proved to best satisfy the design goals and criteria.

\subsection{Selected Entry, Descent and Landing System concept}

The selected MNL EDLS was designed to cope with relative entry speeds of slightly over $6 \mathrm{~km} \mathrm{~s}^{-1}$ for the current design configuration. Higher entry speeds are possible with some adjustments to the aerodynamics. The major components of the EDLS are the hypersonic inflatable braking unit (H-IBU), the transonic inflatable braking unit (T-IBU) and penetrator. The H-IBU is an inflatable heat shield designed to resist the heat during hypersonic entry into the atmosphere and decelerate the vehicle down to slightly below Mach 1 . The T-IBU is an inflatable device known as a tension cone and is designed to decelerate the vehicle out of the transonic region down to fully subsonic speeds. Almost immediately after the 

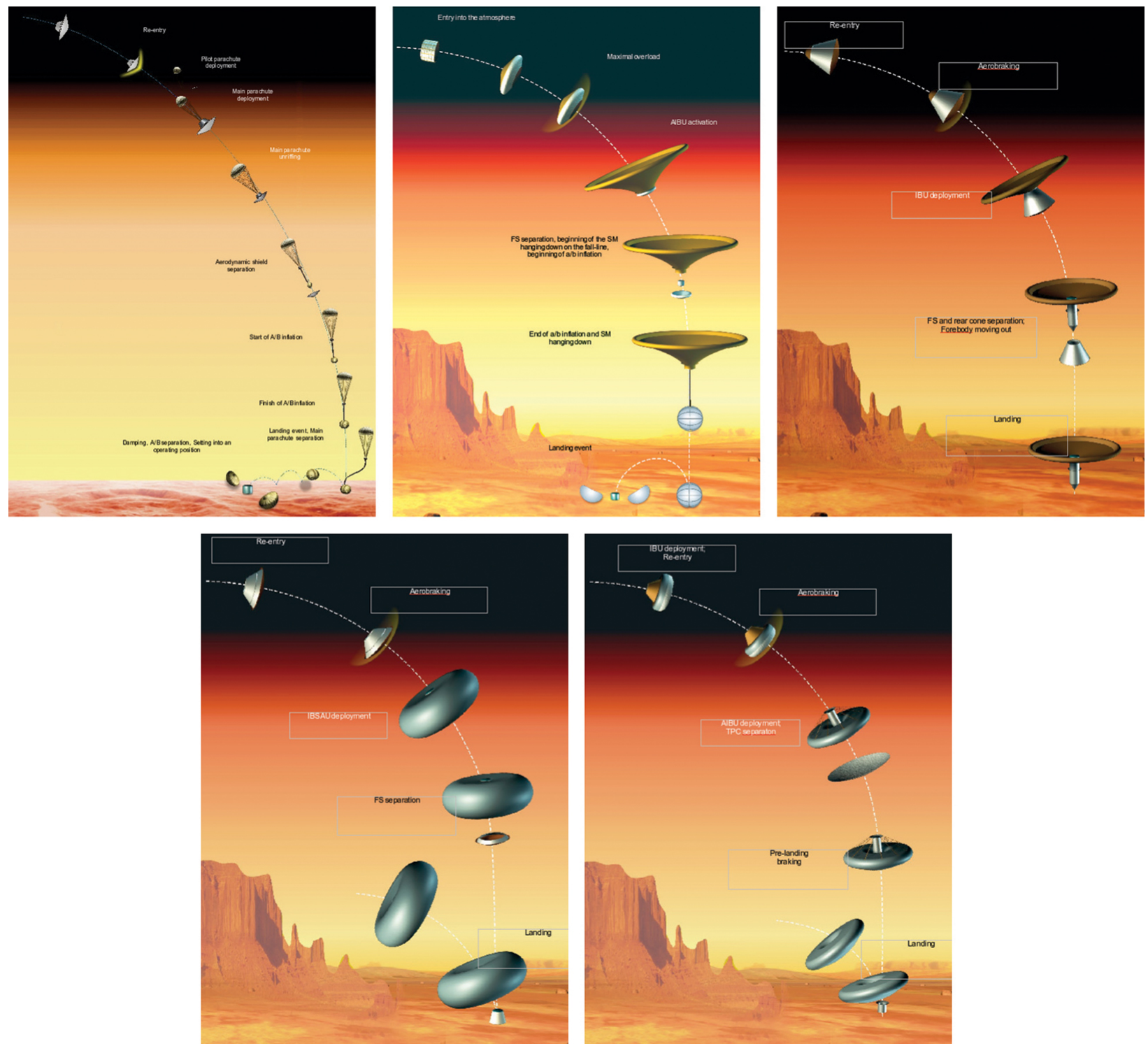

Figure 1. Landing schemes and designs (from left to right and top-down: A1, A2, B1, B2, B3 as in Table 1) investigated during the course of development of the MNL concept.

T-IBU is deployed the H-IBU is jettisoned. Once the H-IBU is jettisoned the forebody (FB) of the penetrator is deployed and locked into place ready for impact with the surface.

A MNL can be separated from the carrier spacecraft either directly from a Mars-approaching trajectory or from Martian orbit. Depending on the mission concept, a single carrier spacecraft may carry and deploy a single or several MNL. During the Earth-Mars cruise and possible orbital injection the carrier spacecraft provides each MNL with communications (data link) and power (for instance for health checks every few months, software upgrades, etc.) through the Carrier Spacecraft Interface and Lander Deployment System (CSILDS). The CSI-LDS features may vary depending on the number of MNLs carried, the mission concept and the char- acteristics of the carrier spacecraft. A proposed MetNet mission with 16 landers (Harri et al., 2007) was made in 2007 as a study for a European Space Agency (ESA) medium class mission. Each lander was allocated a mass of 20 plus $10 \mathrm{~kg}$ for the spin/ejection mechanisms. The mass estimates were given with a margin of $10-20 \%$.

The entry, descent and landing (EDL) sequence of activities, shown in Fig. 2, begins with the separation phase from a few hours to a few days before actual separation from the carrier spacecraft. The MNL batteries (Sect. 3.2) are charged to capacity and depending on what has been performed during the preceding health check, final parameter updates to the Command and Data Management System (CDMS; e.g. software, cyclograms - see Sect. 3.3 and 3.5) may also be made. 


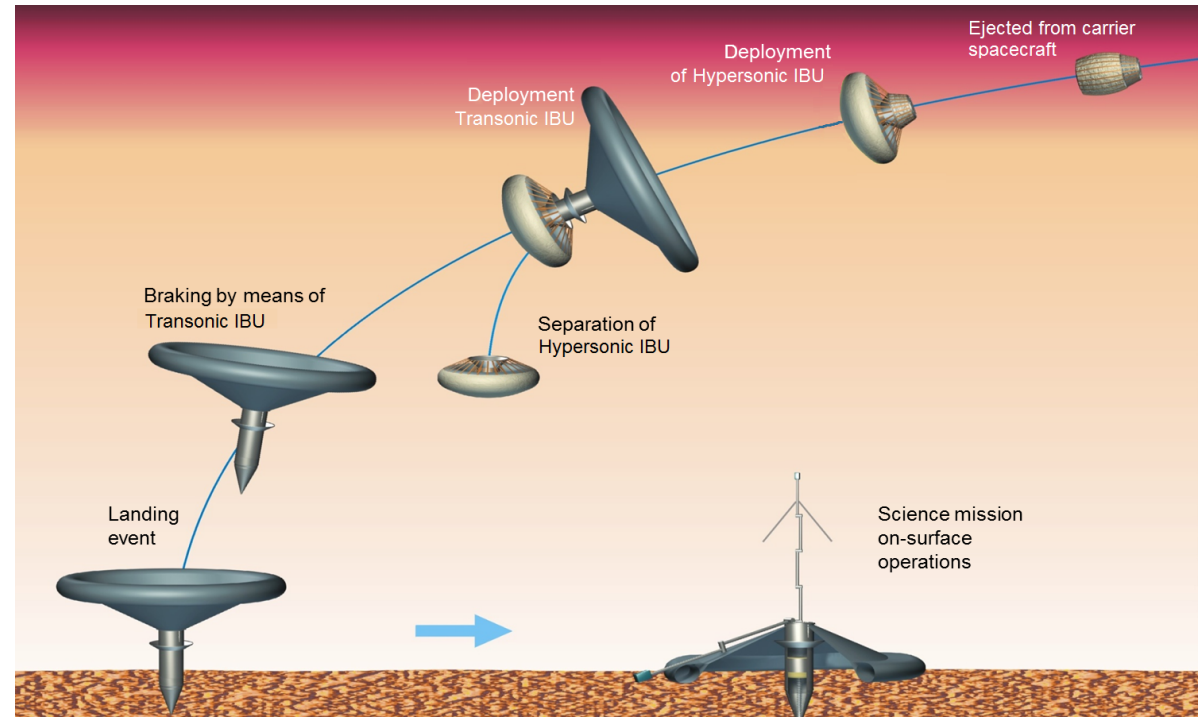

Figure 2. MetNet Lander (MNL) entry and landing sequence and configurations at different parts of the sequence: (1) the complete lander in stowed configuration during cruise and coast phase prior to atmospheric entry; (2) hypersonic inflatable braking unit (H-IBU) deployed for atmospheric entry; (3) transonic inflatable braking unit (T-IBU) deployed, H-IBU and rigid aerodynamic shielding (RAS) not yet jettisoned; (4) surface module (SM) in landing configuration with the forebody deployed.

Just prior to separation the MNL clock is set and the lander is spun up for stability during the entry into the atmosphere. This process takes $<10 \mathrm{~min}$ to complete.

Since the MNL itself does not have thrusters for trajectory or attitude changes, the carrier spacecraft may also need to carry out attitude change manoeuvres to release each MNL at the correct angle and at the correct time to reach its intended landing area. Stability is obtained from the aerodynamic properties of the vehicle and spinning of the MNL. The MNL is ejected and given its spin of one revolution every $6 \mathrm{~s}$ by a spring-loaded mechanism on the carrier spacecraft.

The behaviour of an MNL during the entire EDL is monitored by a combined three-axis accelerometer and gyroscope instrument. This diagnostic information is transmitted in packets in near-real time to the relay spacecraft (the carrier or a Mars orbiter, if one is suitably positioned during the EDL) via two dedicated beacon antennas (Sect. 3.3). The CDMS of the MNL connects the radio system first to the outer beacon antenna, after the inflation of heat shield to a second antenna and after landing and deployment of the instrument mast to the main antenna. The data packets include lander identifiers, and hence the monitoring system permits overlap or concurrence of EDL phases of multiple landers.

The entry phase begins when the MNL senses the first indications of interaction with the atmosphere and ends in the transonic (transition from super- to subsonic) speed regime. The inflatable heat shield is used during the entry phase to stabilise, decelerate the lander and protect it against excessive heat. The heat shield is inflated using a timer after release from the carrier spacecraft. The optimal range for the entry angle is -16 to $-18 \pm 2^{\circ}$. The inflatable heat shield di- ameter is $1 \mathrm{~m}$, which decelerates the vehicle down to a Mach number of about 0.85 at an altitude of $4.5-11.0 \mathrm{~km}$ above the Martian datum, i.e. the point of zero elevation on Mars equivalent to the altitude where the pressure is $610 \mathrm{~Pa}$, and a dynamic pressure of $95-130 \mathrm{Nm}^{-2}$ (both altitude and dynamic pressure depending on the angle of entry). The tension cone is fully inflated and the heat shield released $10 \mathrm{~s}$ later, allowing the vehicle to stabilise.

The descent phase begins when the lander speed is slightly below Mach 1, the inflatable heat shield is ejected and the tension cone is deployed. The tension cone diameter is $2 \mathrm{~m}$, and is used to decelerate the MNL down to a landing speed of $47-55 \mathrm{~m} \mathrm{~s}^{-1}$, depending on the angle of entry, at the Martian datum. The descent phase ends with the contact of the penetrator tip with the surface. Peak deceleration of the MNL payload bay during the impact will be $<500 \mathrm{~g}$, with the outer shell experience about twice the load on the payload, and the total impact time is $20 \mathrm{~ms}$. The minimum impact speed required for an operational landing is $50 \mathrm{~m} \mathrm{~s}^{-1}$ with a maximum horizontal wind speed of $20 \mathrm{~m} \mathrm{~s}^{-1}$.

The landing phase begins when the tip of the penetrator touches the surface and ends when the lander has come to rest on and is partially embedded in the top layers of the surface. The deceleration experienced by the payload as the lander penetrates the surface is of the order of $500 \mathrm{~g}$. The structures and mechanisms involved in the final phase landing process, comprising of the shock absorbing system (SAS), which is used to reduce the g-levels on the instruments, are described in greater detail in Sect. 3.1. 


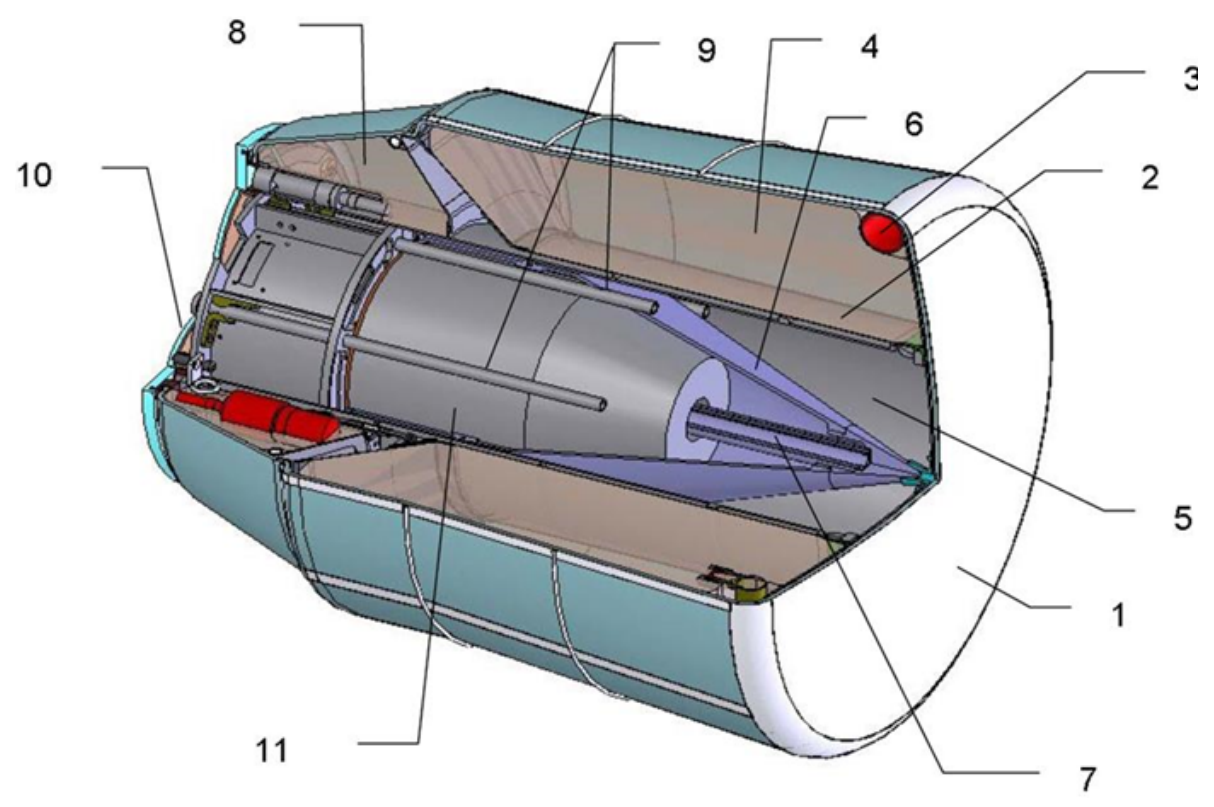

Figure 3. The rigid aerodynamic shielding (RAS) includes a blunt front shield plate, a toroidal pressure vessel (which stores the H-IBU inflating gas under pressure) as well as supporting structures for both the surface module and the entry and descent systems. The labels are as follows: (1) front shield (FS) with TPC; (2) body of FS; (3) H-IBD filling system; (4) H-IBD; (5) lander body; (6) telescopic cone; (7) telescopic cone drive; (8) T-IBD; (9) shock absorber; (10) cover; (11) instrument container.

\section{Description, operation and testing of the prototype hardware}

\subsection{Structures and mechanisms}

The MNL mechanisms are divided into two categories which are (a) the entry, descent and related subsystems and (b) the landing and surface operation-related subsystems. The entry and descent system consists of three subsystems:

1. rigid aerodynamic shielding (RAS) and supporting structure,

2. flexible heat protection (FHP) and

3. H-IBU (see Sect. 2.3), inflation system and load-bearing elements.

The landing and surface operation system consists of three subsystems:

1. T-IBU and gas generator,

2. surface module (SM) with a SAS and

3. equipment compartment (EC).

During cruise, entry and most of the descent phase, the EDLS-related subsystems and the SM are efficiently packed in terms of volume. This is achieved by stowing the systems telescopically inside each others where possible. The FB is stowed inside the SM cylindrical structure. When the FB is deployed the empty space provides room for the deceleration of the EC along a set of crushable rods during the impact with the surface. The FB will be deployed into a landing configuration after jettisoning the H-IBU. The stowed SM and FB are both stowed inside the mechanical support cylindrical structure of the rigid section of the front shield during entry and upper atmosphere braking phase. Figure 3 shows the complete lander with empty stowed H-IBU wrapped around it.

The SM accommodates the system electronics and payload instruments. The T-IBU is connected to and surrounds the SM. These three subsystems stay interconnected after touchdown forming the surface operating unit. The power system solar cells are attached to the upper surface of the T-IBU. Other subsystems, forming most of the EDLS, are ejected during the descent phase as shown in Fig. 2.

The SM accommodates the EC, which houses the system and payload electronics and supports external sensors (the boom with meteorological sensors, optical sensor) and telecom antenna. The SM includes a rear cover lid, which protects the module during entry and landing.

The SM includes the SAS. This system allows the equipment module (EM) to slide some tens of centimetres during the impact with the surface and thus reduce the deceleration experienced by the equipment module by a factor of around 2 compared to other rigid mechanics such as the surface module body structures. The SAS is made of six metallic (AMg3M aluminium-magnesium alloy; GOST, 1977) hollow tubes. The equipment module slides along these tubes during the impact on the surface and kinetic energy is re- 
(a)

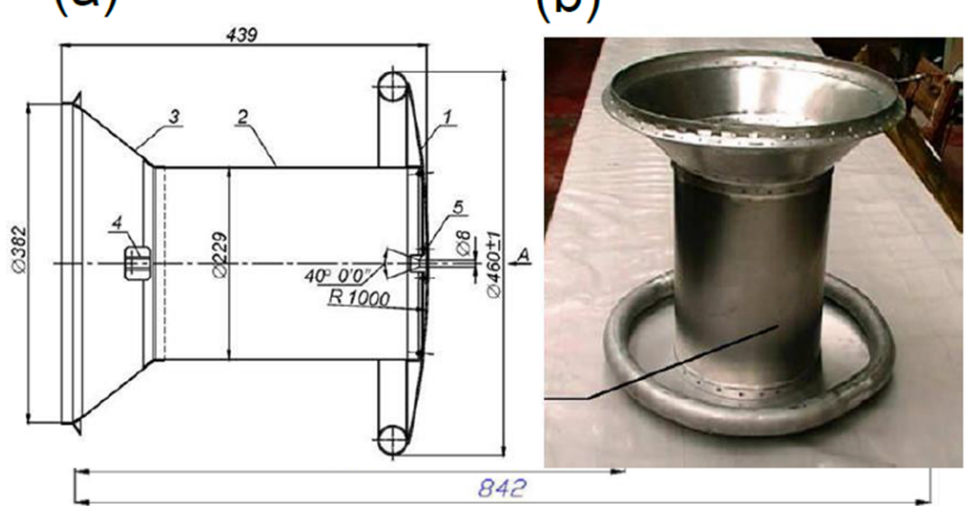

(c)

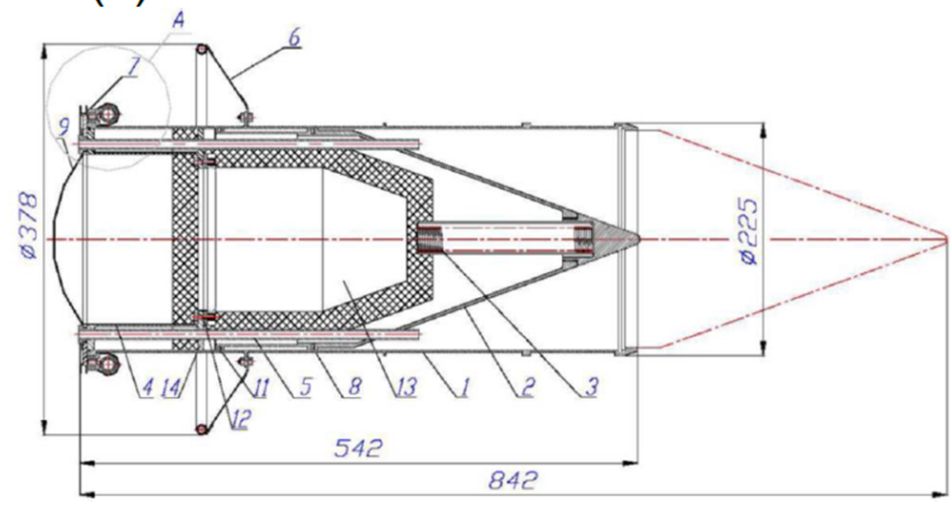

Figure 4. The top two figures show the rigid aerodynamic shielding (RAS), which includes blunt front shield plate, toroidal pressure vessel, which stores the H-IBU inflating gas (under pressure), and supporting structures for the surface module and entry and descent systems. Image (c) shows the SM in stowed configuration: (1) main body; (2) conical forebody; (3) spring to deploy forebody; (4) IB; (5) deforming tubes; (6) conical structure; (9) lid for protecting external and deployable instrumentation; (13) EM.

duced by squeezing the hollow tubes flat by squared sliding slots of the equipment module supporting adapter.

\subsubsection{Entry- and descent-related subsystems}

The RAS including structural details is shown in Fig. 4. The SM with stowed FB fits inside the cylindrical and conical structure. Figure $4 \mathrm{c}$ shows the SM with the FB extended. The surface module and RAS are connected and secured together by a cable and two turn-buckle devices. The RAS blunt circular front shield has radius of curvature of $1.0 \mathrm{~m}$ and a diameter of $0.46 \mathrm{~m}$. The RAS is manufactured from $\mathrm{AMg} 6, \mathrm{AMg} 6 \mathrm{M}$ and MA2-1 aluminium-magnesium alloys. The H-IBU interfaces with the RAS by a H-IBU inflation system (H-IBU-IS). H-IBU-IS includes a toroidal pressure vessel for storing the H-IBU inflation gas and required pyrooperated valves. The toroidal H-IBU-IS can be seen in Fig. 5 surrounding the circular front shield. The RAS has total mass of $2.31 \mathrm{~kg}$.

The H-IBU consists of a toroidal inflatable wheel, shown in Fig. 5b, which supports the flexible thermal protection system (TPS), increases the frontal braking area and maintains the stability and flight path angle during early landing phase within specifications. The H-IBU consists of 12 tubular segments, each with a diameter of $250 \mathrm{~mm}$. The total diameter of the complete inflated $\mathrm{H}-\mathrm{IBU}$ is $1000 \mathrm{~mm}$. Inflation pressure is $63 \mathrm{~Pa}$. The H-IBU consists of an internal gas-tight bladder (TPM-8 fabric), external cover fabric (aramid fibre), load bearing tapes, filling hoses as well as hardware and accommodation bag. Total mass is $1.17 \mathrm{~kg}$. Figure $5 \mathrm{c}$ shows the inflated $\mathrm{H}$-IBU.

\subsubsection{Landing and surface operation-related subsystems}

The T-IBU, shown in Fig. 6, is used during the last stages of the descent and landing. The T-IBU is deployed just before jettison of the combined H-IBU and RAS and supporting structures. The T-IBU decelerates the MNL down to subsonic speed and stabilises the lander. After landing T-IBU also supports the solar panels, which are mounted on its surface.

The T-IBU consists of toroidal shell cover and gas-tight bladder, flexible cone and inflation system which is based on a pyrotechnical gas generator. The toroidal part of the T-IBU 
(a)

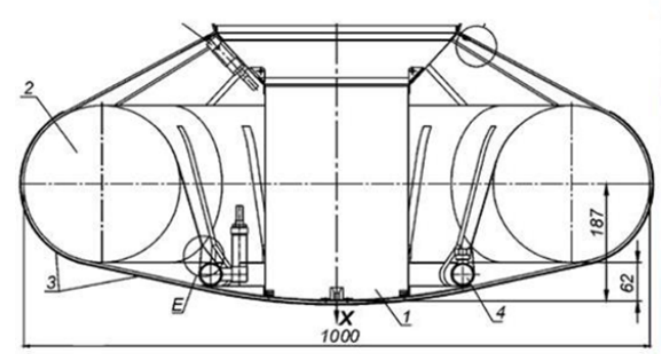

(b)

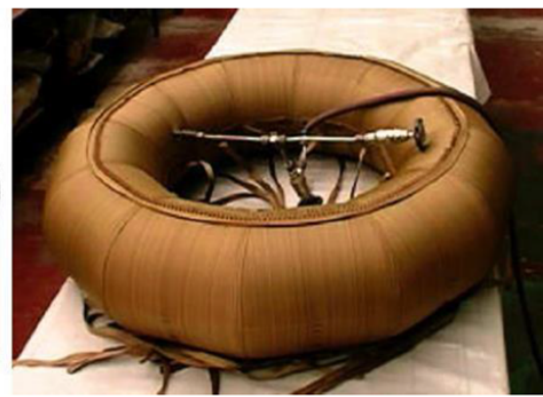

(c)

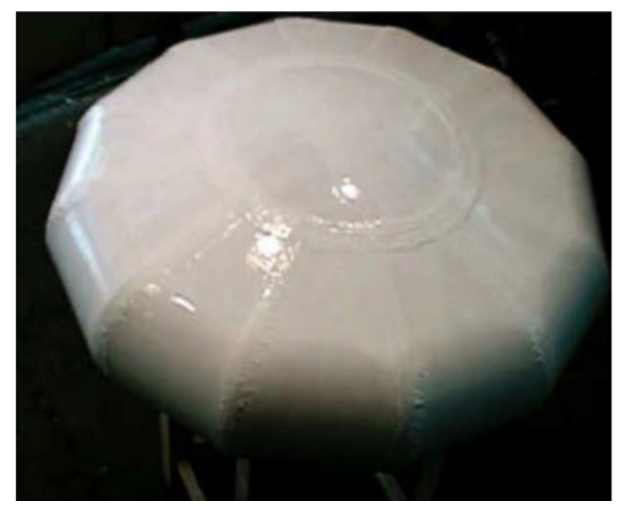

Figure 5. Images (a) and (b): main inflatable braking unit (H-IBU) in the drawing on the left is a toroidal inflatable wheel (4), which supports the flexible heat protection system (3) and maintains required shape for maintaining correct attitude and flight path angle. Torus shaped pressure vessel/pressure receiver (4) provides required inflation gas. Inflated H-IBU assembly with the cover shell is shown on the right. The bottom figure shows the thermal protection shell (TPS) deployed. It is supported by the rigid section of frontal shield in the middle and toroidal inflatable H-IBU constructed from 12 segments.
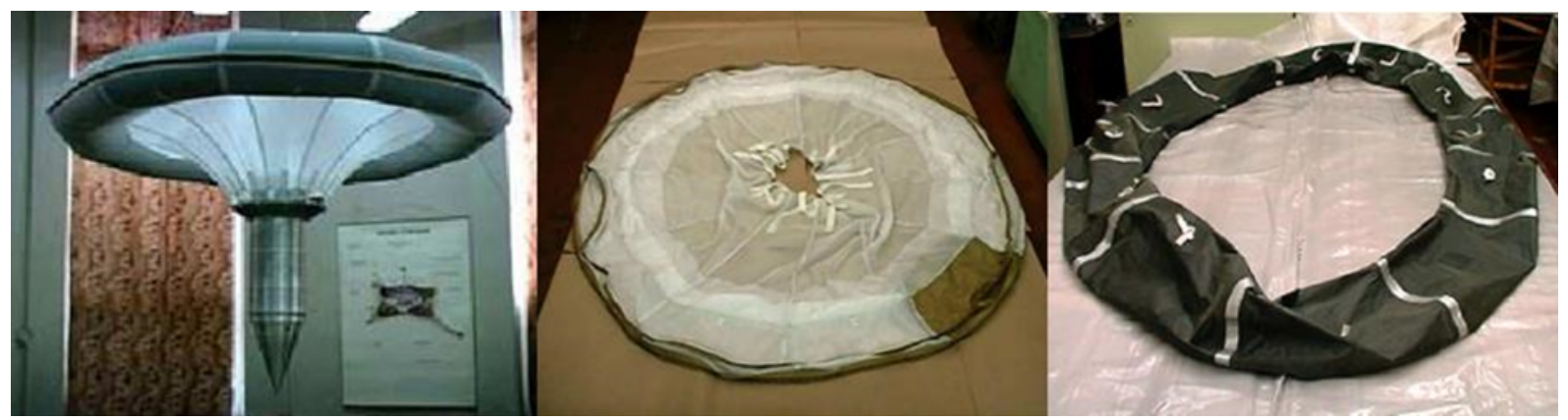

Figure 6. Inflated additional inflatable braking unit (T-IBU) shown on the left with the surface module (SM). In the centre the cover of the T-IBU and on the right the gas-tight bladder.

is made up of 12 segments with each segment having a diameter of $200 \mathrm{~mm}$. The inflated T-IBU has an overall diameter of $1800 \mathrm{~mm}$. The T-IBU hardware is accommodated into a cone shaped upper part of the external body of the SM. The T-IBU has a mass of $1.06 \mathrm{~kg}$.
The SM is the final stage. The surface module consists of the EM, internal body (IB), the FB and the main body (MB). They are made of $\mathrm{AMg} 6$ aluminium-magnesium alloy.

The FB is conical and is a telescopically extending ground-penetrating forward section of the surface module. During the last stage of deployment the forebody is locked together with the MB thus forming a unified structure. The IB is a cylindrical compartment inside the upper section of the MB. The IB is mounted together with the EM below it. The IB accommodates the external deployable instrument boom. 


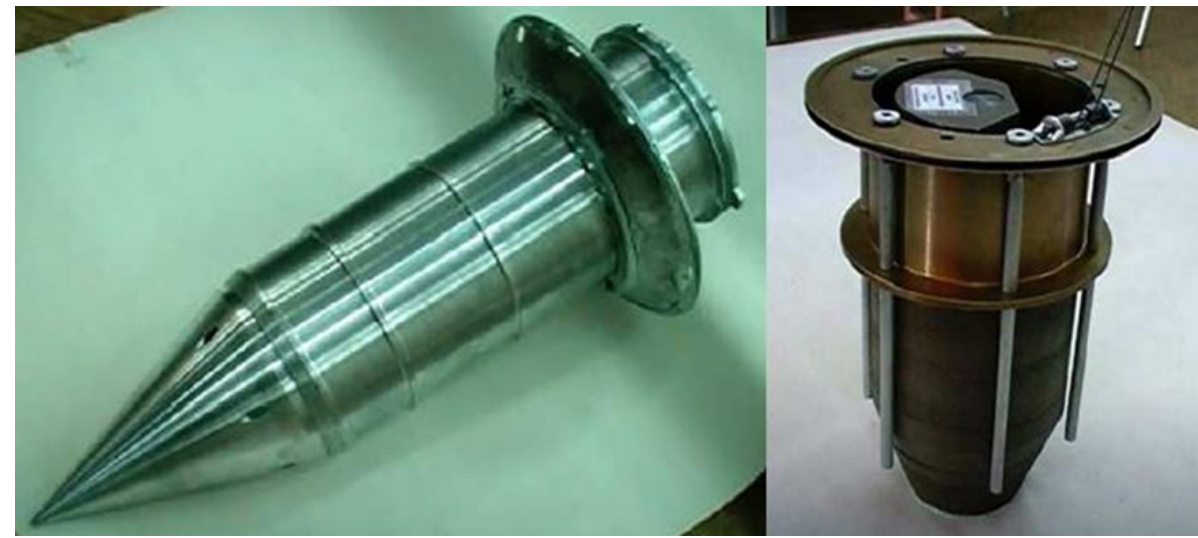

Figure 7. On the left is the surface module forebody deployed. On the right is the internal body together with equipment module mounted below it. Shock absorbing system tubes are visible. The hollow tubes absorb kinetic energy by deforming as they slide through too-small openings on the flanges of the internal body.

The EM is sealed and thermally insulated from the environment and accommodates electronics.

The SAS is installed inside the MB (Fig. 7a) and is designed to reduce g-loads on the payload compartment. The SAS is based on six deforming hollow tubes, which can be seen in Fig. 7b, mounted inside the MB. These tubes support IB and EM, which during landing impact slide along these tubes. The IB has narrower guiding slots for the tubes than their external diameter. The tubes will thus be deformed narrower accordingly and absorb the kinetic energy from the EM during the impact with the surface. The IB and EM can decelerate over a distance that is $30 \mathrm{~cm}$ more than the combined $\mathrm{MB}$ and $\mathrm{FB}$. Using this method the deceleration can be limited to a maximum of $500 \mathrm{~g}$. The tubes are made of aluminium-magnesium alloy $\mathrm{AMg} 3 \mathrm{M}$.

Figure 8 shows the configuration of the MNL's internal and external components just before and after landing. In Fig. 8b the payload compartment (EM and IB) has slid downwards along the six deforming hollow tubes.

The payload compartment consists of the EM and IB mounted together. The EM is sealed inside thermal insulation and accommodates most of the payload electronics and batteries. On the top of the EM is the IB, which accommodates the instrument boom. The boom supports temperature and humidity sensors as well as the camera and optical sensor. The boom also supports the telecom antenna. The IB features the interface with the SAS as described earlier. Figure $8 \mathrm{c}$ shows the payload compartment.

\subsection{Electric power and thermal management subsystems}

The primary power source for the MNL baseline design is solar energy. Flexible $\mathrm{Si}$ solar cells with cell dimensions $11.4 \mathrm{~cm} \times 4.6 \mathrm{~cm}$ and total area approximately $400 \mathrm{~cm}^{2}$ are placed in pockets sewn on the fabric of the upper side of the T-IBU. The cells provide daily average electrical power of about $600 \mathrm{~mW}$. Energy storage of about $40 \mathrm{Wh}$ is provided by two SAFT MPS176065 Li-ion batteries connected in series inside a thermally sealed container. Originally inclusion of radioisotope thermal generators (RTG) into the basic design was investigated and consequently the design does accommodate them. The RTGs were dropped, however, due to anticipated Precursor mission options, due to difficulties related to availability of the devices and due to environmental impact assessment, political and security issues related to launching radioactive materials and devices.

This baseline non-RTG power system design limits operations to latitudes effectively between $\pm 30^{\circ}$ about the Equator and even within that latitude band night-time operations will be highly constrained by available power. During times of increased opacity of the atmosphere due to dust storms, during local winter time at higher latitudes or in case parts of the solar cells are covered by dust, the generated electrical energy will be reduced, limiting the operational possibilities further. Inclusion of a RTG would allow for more continuous and robust operations as well as landing sites and operations also during wintertime at higher latitudes, up to polar regions.

The rather limited amount of power (ultimately dissipated as heat necessary for thermal management) provided by the non-RTG power system is partially compensated by the passive thermal control inherent in the penetrating MNL design: after a successful landing the front part is submerged in the Martian soil and in good thermal contact with its surroundings. Since the amplitude of the temperature variations tends to decline fairly rapidly with increased depth for undisturbed material (Fig. 9). This results in smaller thermal variations for those payload components and lander subsystems housed in the front part of the lander (Paton et al., 2016). The MNL battery can operate down to temperatures of $220 \mathrm{~K}$ and will have its own additional thermal insulation and heaters to increase the battery temperature during charging to at least $250 \mathrm{~K}$ if needed. The parts and subsystems remaining above 


\section{(a)}

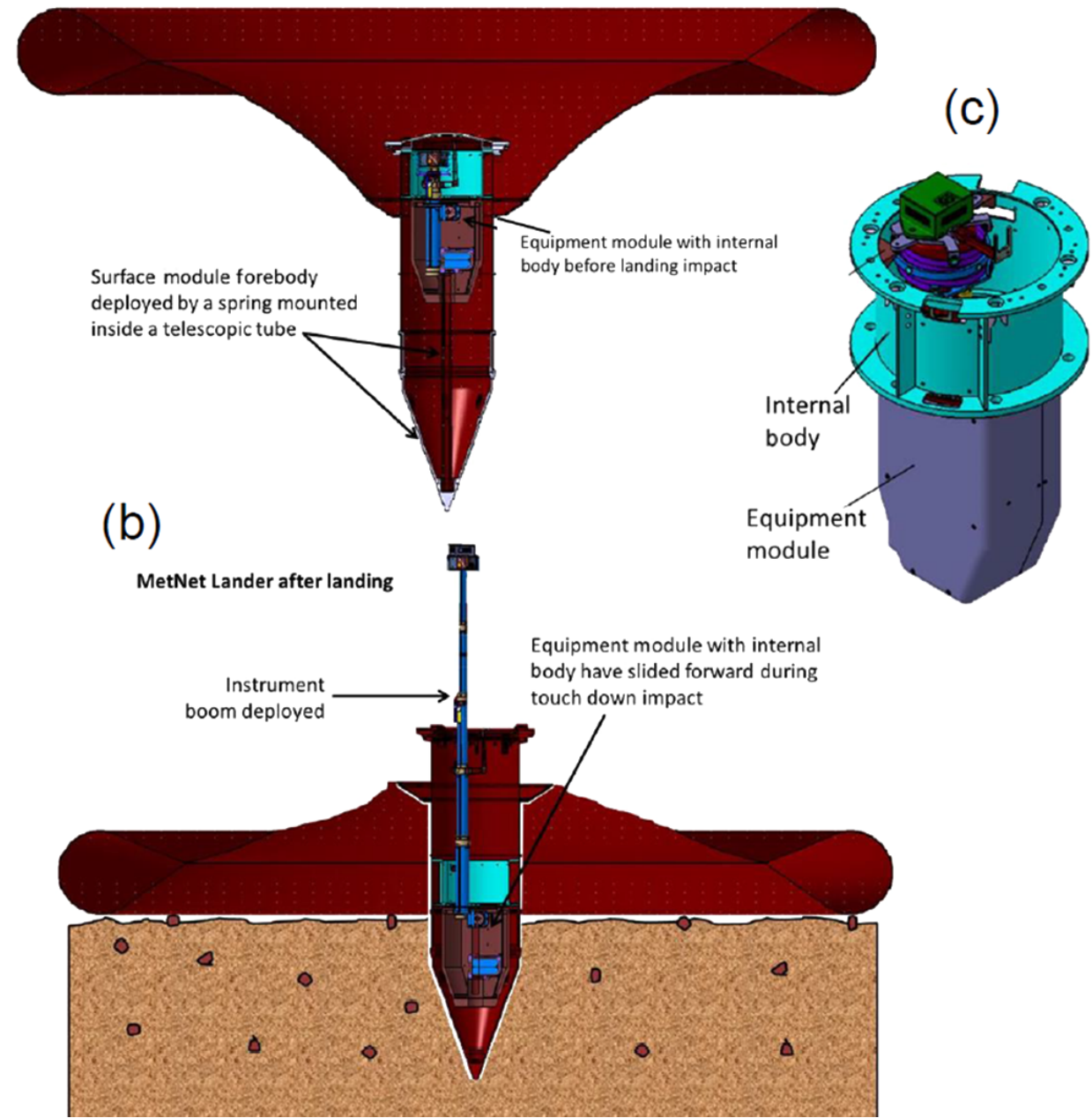

Figure 8. Image (a) shows the configuration of the external and internal components of the MNL in the last stage of the descent before impacting the surface. Image (b) shows the configuration of the same components after impacting the surface. Image (c) shows a perspective view of the internal body and equipment module.

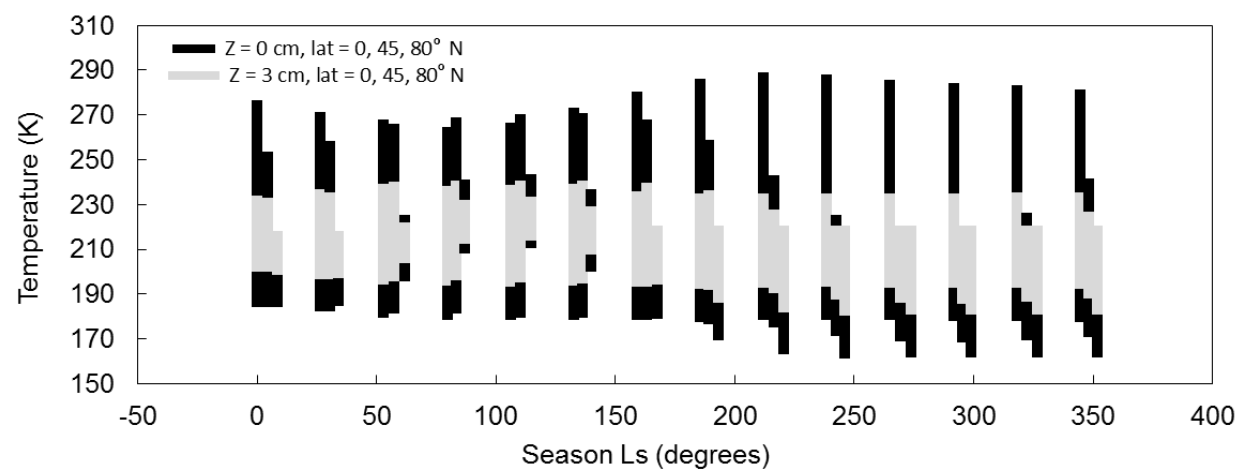

Figure 9. The range of temperatures experienced at different latitudes and depths on Mars over the Martian season in material undisturbed by the MNL. The light black bars represent the surface temperature and the grey bars represent the temperature at a depth of $3 \mathrm{~cm}$. The bars a grouped together in bunches of three representing the three different latitudes modelled: 0,40 and $80^{\circ} \mathrm{N}$. 


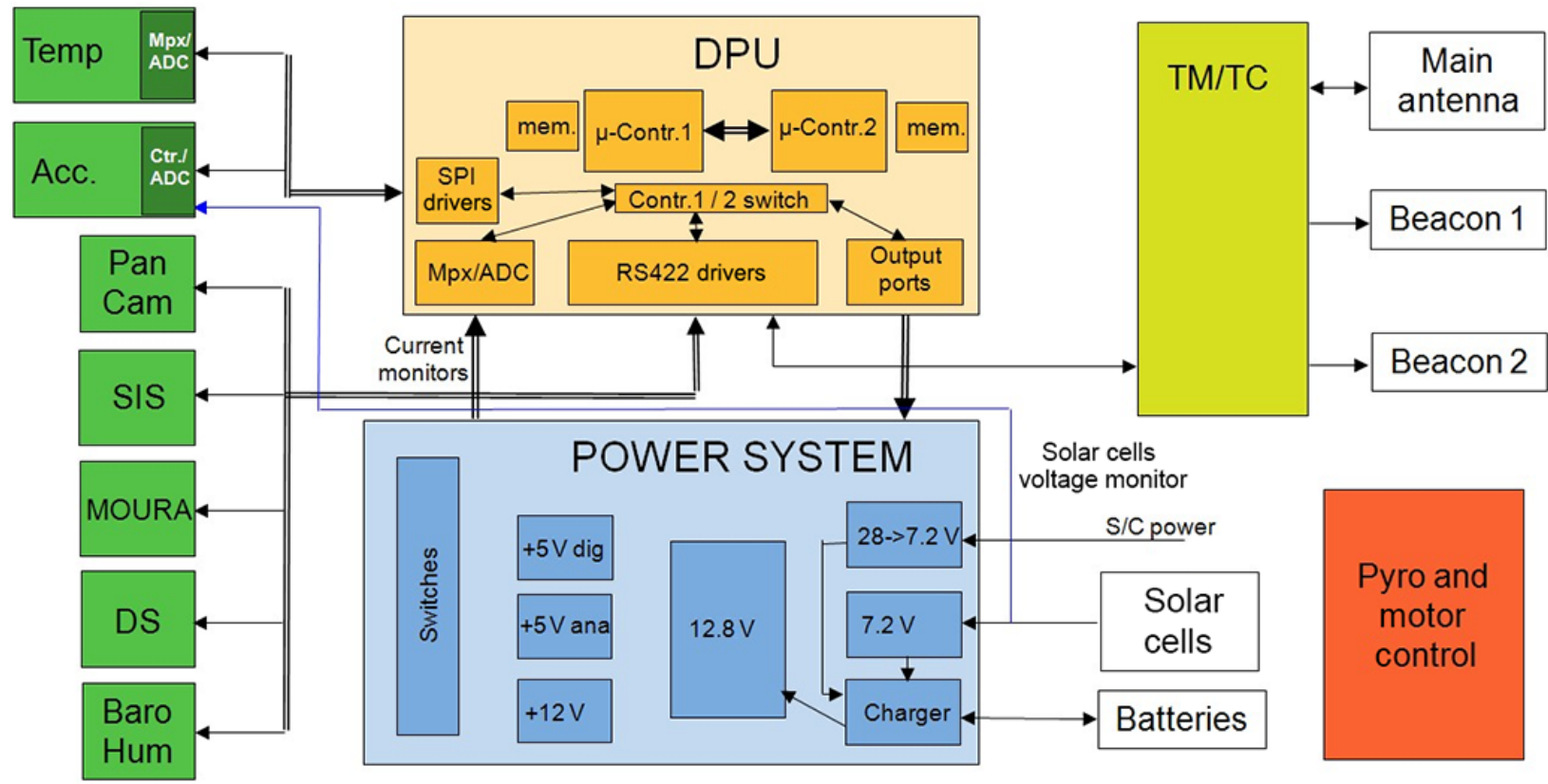

Figure 10. The MNL electronics consists of a hot-redundant microcontroller with duplicated interfaces, a power conditioning and a radio system. Communication with the detectors is via serial links.

the surface face comparatively much harsher thermal environment.

\subsection{Communications, CDMS and electronics}

The MNL does not include direct MNL-Earth communications capability - a relay spacecraft (either the carrier spacecraft during Earth-Mars transit or a Mars orbiter) is required. Observational and housekeeping data are preprocessed (including image compression) on board the MNL and transmitted to a relay orbiter on the UHF band. The radio system is built around the same type of micro controller used in the CDMS. Together with an field-programmable gate array it implements the Proximity 1 protocol (CCSDS 211.0-B-4) (for compatibility with the current and likely future Mars orbiting platforms). The system supports a bi-directional data link while still connected to the carrier vehicle, allowing a full system checkout as well as last-minute adjustments of operational parameters. The communication system is also capable of supporting a bi-directional link. There is also a technical capability to support software updates.

Operations are designed to make sure the transmitter does not drain the battery. The MNL goes into idle mode to save energy. The clock continues running. At preplanned times the lander waits for a hail signal from the orbiter before transmitting data.

The battery status monitor together with the systemrelated part of the software assures that enough energy remains available to perform the essential system tasks like telecommunication link during times of orbiter visibility, as well as time keeping. Surface to orbit link is around $16 \mathrm{kbps}$. The overall data transfer rate is expected to be low: about 0.25 to $0.75 \mathrm{Mb} \mathrm{day}^{-1}$ on the average, depending on the orbital configuration.

The CDMS is built around a fully redundant micro controller system where one system is capable of autonomously detecting and correcting errors in the performance of the active controller. The micro controller type used is a free-scale micro controller MC9S12XEP100. The micro controller has $1 \mathrm{MB}$ flash PROM for program, $64 \mathrm{kB}$ RAM for data, $4 \mathrm{kB}$ EEPROM and $32 \mathrm{kB}$ D-flash. External memory used in the MetNet DPU is $2 \times 128 \mathrm{Mbit}$ serial flash memory. The same type of micro controller is used for DREAMS aboard ExoMars 2016.

All hardware interfaces and memories are duplicated so that the secondary controller can operate the system completely in case the primary one malfunctions without correction possibility. A block diagram is shown in Fig. 10. The software and even the controller hardware configuration can be updated from the operational controller via the implemented JTAG (Joint Test Action Group) input, using the own configuration as reference. The monitoring between the redundant controllers is done by a bi-directional CAN-bus interface integrated into each of the controllers. This link is also used to update cyclogram contents in the secondary controller after a commanded update.

Each of the MNL sensors are required to pre-process its observational data including image compression inside the panorama camera. The controller itself does not include any 
general data compression software to minimise especially energy resources.

\subsection{Payload resources and strawman payload}

With a total of $4 \mathrm{~kg}$ for the payload including $2.6 \mathrm{~kg}$ for the control system and meteorological mast including antennas, $1.4 \mathrm{~kg}$ are available for the instruments. As instruments are normally not operated in parallel the maximum available current from the batteries has only to be shared between the $\mathrm{CPU}$ and one sensor. With a maximum current of $5.8 \mathrm{~A}$ at $2 \times 3.5 \mathrm{~V}$ about $40 \mathrm{~W}$ maximum power is available for a short time (of the order of $1 \mathrm{~h}$; see also Sect. 3.2). The average power used has to be balanced against the average power provided by the solar cells and limits the time an instrument can be operated per sol. Instruments and their electronics can be accommodated either inside the thermally stabilised payload compartment guaranteeing temperatures above $-50^{\circ} \mathrm{C}$ or outside on or close to the telescopic mast. The payload compartment is illustrated in Fig. 11.

The MNL operations will be defined such that the average energy consumption does not exceed the energy provided by the solar panels. The main energy drain is the transmitter, which is used at such intervals that allow the charging of the battery between transmissions. The MNL components allow for such operational cyclograms to be defined.

The strawman payload for the Precursor mission includes sensors for temperature, pressure and humidity measurements, a four-lens panoramic camera, a multi-band spectrometer with $2 \pi$ view, a three-axis magnetometer, a dust sensor and a combined three-axis accelerometer/three-axis gyrometer for descent control and monitoring.

\subsection{MNL operations}

Since commanding of a MNL is probably possible only infrequently if at all, a highly autonomous operations concept is necessary. The driving design factors constraining the vehicle design are optimal utilisation of the limited energy and availability of telemetry link time. The system also has to be able to adapt to different environmental conditions (e.g. day/night) and correct or minimise impacts of system problems. The general control scheme is illustrated in Fig. 12.

Due to the limited power supply, telemetry sessions exclude simultaneous observations. Phobos' eclipse observations (see end of this section) will also take precedence over regular observations.

The system software is implemented as a linear process, started at regular intervals of about $20 \mathrm{~ms}$ out of a low-power standby mode, checking first the battery status, then the availability of a telemetry link. If either the energy level is dangerously low or a telemetry link is possible, any science operation is aborted and all sensors are powered off. Telemetry remains switched on as long as relay link energy and non-transferred data are available. At other times observa-

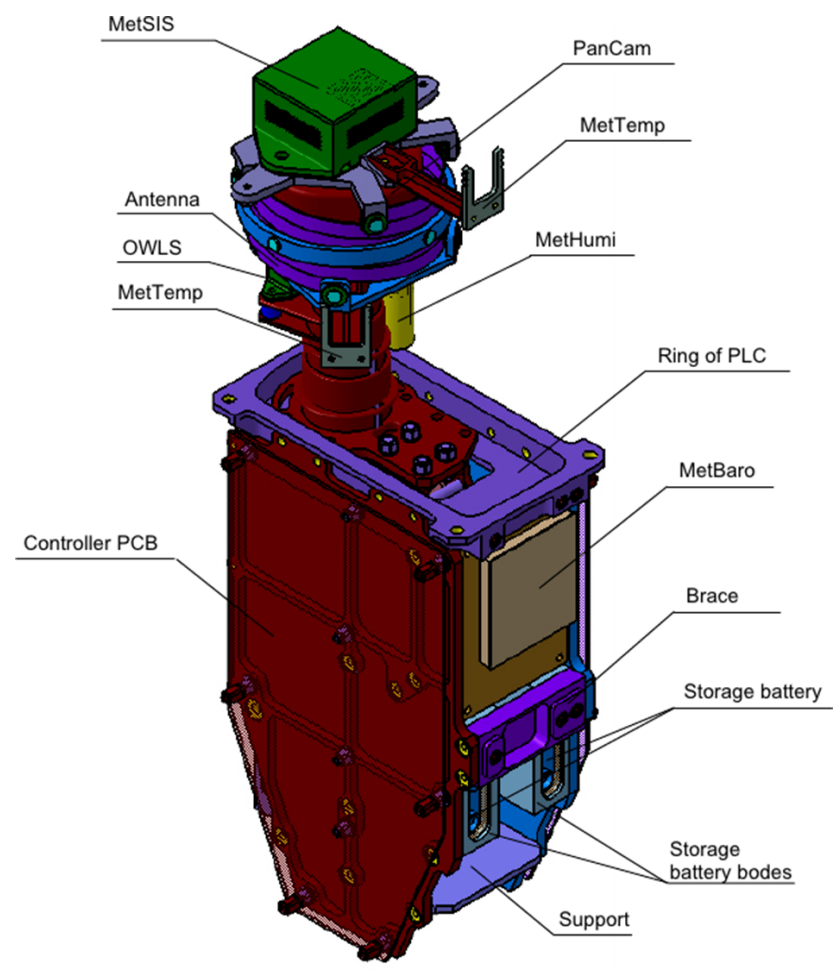

Figure 11. The payload compartment of the MetNet Lander slides after impact some $30 \mathrm{~cm}$ with deforming struts absorbing the kinetic energy remaining at the time of impact. All the instruments are packed tightly together with the CDMS and other system electronics.

tions are carried out according to a cyclograms concept. As up to 20 cyclograms - specifying detailed timing and command sequences for the sensors - can be defined, a sufficient set of scenarios can be covered. Cyclograms can be updated, if commanding is available. The concept allows consolidation and freezing of the system software at an early stage for testing while the detailed operational sequences may be optimized at least up to close to lander separation.

Concerning the electrical energy, battery charging from the carrier spacecraft or from the solar cells is completely controlled by hardware. Information flow between the controller and sensors or the telemetry system is handled by an independent processor inside the controller. This processor handles real-time tasks like sending of commands or reception of data packets, their consistency checks and acknowledgements. As conversion between internal parallel data words and external serial bit streams is also handled by autonomous hardware inside the controller, the processor is most of the time in standby mode, reducing the energy needs.

Each cyclogram is stored as a matrix with a control header, followed by many fixed-length command vectors. The header contains conditions under which the cyclogram may be used and a pointer to the next command vector to be executed. Additionally each vector defines the time delay to the fol- 


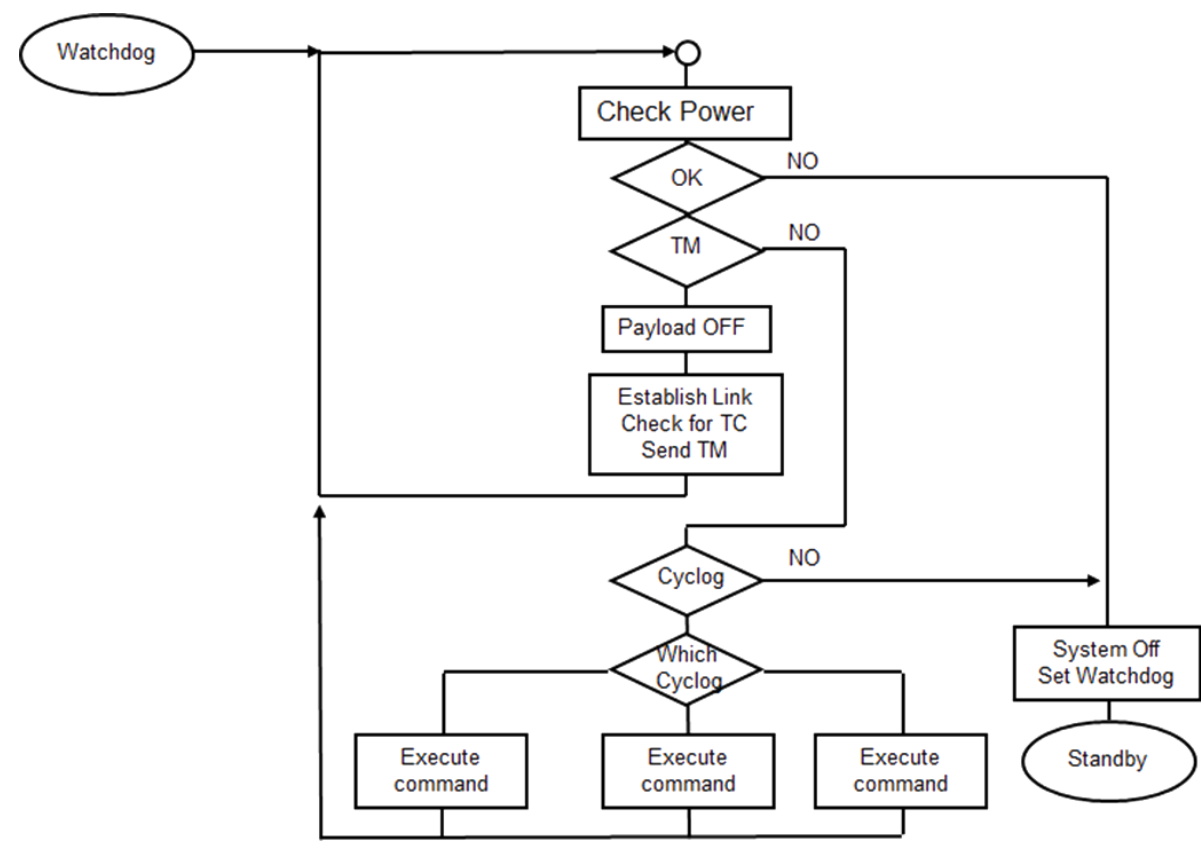

Figure 12. The control system consists of an infinite loop with first a sequence of resource checks, followed by the execution of the next cyclogram command if possible. In between activities the controller is in low-power wait state.

lowing vector and a set of conditions under which this vector has to be skipped. This way the same cyclogram can be used under different conditions like day or night, solar incident angles dangerous for an optical sensor or in case one of the addressed sensors is defective. The command itself contains the address of the system part or sensor, the command code itself and possibly a number of parameters associated with the command. In case the parameter list is too long to fit into the short vector space, the list is replaced by a pointer to a list at the end of the main matrix. To simplify writing and verification of the cyclogram details, the most common command combinations are hardcoded as macros and can be called directly from inside the cyclogram like a direct sensor command, shortening the cyclogram significantly.

The adaptivity of the system is based on the condition flags used to select a given cyclogram and to possibly skip a command vector inside the active cyclogram. The cyclogram control system interprets general system conditions and some of the detector measurement data to define the status of these flags. As the different cyclograms contain possible combinations of sensor operations, mainly sequential but possibly also simultaneous, an additional adaptive priority scheme ensures that each sensor gets a just share of the observation time suitable for its operation. A change in environmental or system conditions during the execution of the main control loop may result in the currently active cyclogram being aborted: the related sensors are switched off and the next possible cyclogram started. This ensures a maximum scientific return with the available resource limitations.
Criteria based on sensor measurements can be refined by programmable algorithms defining the upper and lower limit of these parameters before a condition change is initiated. The most important selection criteria are listed in Table 2 and additional criteria can easily be implemented.

A special case is observation of Phobos' eclipses, used to locate the actual landing site with high precision (Romero et al., 2011; Harri et al., 2012; Barderas and Romero, 2013). This in turn allows for correlation of the time stamps of the data with the correct local time, thereby making comparisons between observations from different landers more precise.

A time window for the passing of Phobos' shadow and for the high-time-resolution measurement with the optical sensor at the top of the mast needs to be determined and preprogrammed into the MNL control system. This can be calculated once the landing area is known based on the trajectory of the transfer vehicle and the scheduled moment of release of the lander. Only daytime passes are observed and only one diode will be used to keep the data amount as low as possible. This eclipse mode is controlled directly by the system software outside the cyclogram scheme. When the programmed absolute time is reached, the active cyclogram is aborted and the macro-like eclipse program with a finite loop is started. The data stored overwrite the not yet transferred data from other sensors if necessary. The measurement is repeated three times about $7.5 \mathrm{~h}$ apart to cover the theoretically expected three subsequent eclipses.

A sampling frequency of $1 \mathrm{~Hz}$ is used as a compromise between precision and generated amount of data inside the needed measurement window. This leads to a resolution of 
Table 2. Environmental or system status cyclogram selection criteria.

\begin{tabular}{ll}
\hline Criterion & Determination \\
\hline Low battery status & Information comes directly from the power subsystem. \\
& Can be used to activate only sensors with low energy \\
& needs (e.g. $T, p, H$ ) when the battery charge is low but \\
& not yet critical. \\
Critical battery status & Information comes directly from the power subsystem. \\
Data buffer availability & The telemetry handling system keeps track of the data \\
& buffer usage per sensor. If the usage limit is reached, the \\
& sensor will be disabled and related commands skipped \\
& in active cyclograms until data have been uplinked and \\
& space made available. This limitation can be ignored to \\
& allow collection of large amounts of data under special \\
conditions. & To save energy and time resources, a detector is dis- \\
abled if it repeatedly fails to react on commands appro- \\
priately. Recovery will be tried once per sol or after a \\
system failure with subsequent reboot. \\
Determined from data from the optical sensors at the top \\
of the mast. During the night the camera and the optical \\
sensor will be disabled. \\
Based on accelerometer data the solar incident angle to \\
the infrared dust sensor is calculated disabling its ope- \\
ration when directly illuminated. \\
Humidity sensor data allow for selection or de-se- \\
lection of the optical sensor $\mathrm{H}_{2} 0$ spectral band.
\end{tabular}

approximately $3 \mathrm{~km}$ depending somewhat on the latitude of the actual landing side, e.g. see (Harri et al., 2012). The clock precision and stability is 5 orders of magnitude better than this, so it can be ignored. The $1 \mathrm{~Hz}$ sampling rate is hardcoded in the software outside the cyclogram control system to allow absolute time scheduling.

\subsection{Aerodynamic and aerothermodynamic considerations}

The aerodynamic and aerothermodynamic properties important for the design of the EDLS and trajectory have been studied in detail for MNL using laboratory tests and numerical modelling. Both the MNL with the heat shield inflated and the MNL with the tension cone deployed have been studied with wind tunnel tests and computer models to determine their aerodynamic, dynamic stability and static stability coefficients. Structural analysis of the penetrator during impact with the surface has been conducted using computer modelling and laboratory impact tests. Arc-jet tests have been made of the MNL TPS. In addition, computer modelling of the heat shield surface and payload temperatures has been performed during the descent. Computer modelling was used to assess the thermal response of the T-IBU during the descent.

The thermal protection system shown in Fig. 13 consists of three sections. Section I covers the rigid central frontal struc- ture and the inflated torus structure around the central compartment. Section I is constructed of a double layer of KT-11 cloth, a glass-cloth-based laminate (Shalin, 1995), that can survive temperatures up to $1500 \mathrm{~K}$. The exterior surface of the outer layer of the cloth is covered with a $1-1.3 \mathrm{~mm}$ thick layer of material that can absorb the heat experienced during atmospheric entry by sublimating. The sublimation temperature for this material is $950 \mathrm{~K}$. Multi-layer insulation (MLI) is situated under the KT-11 cloth layers and is covered with a glass fabric that can survive short duration temperatures of $750-800 \mathrm{~K}$. Figure 14 shows the modelled temperatures of the MNL at a speed of Mach 1.3.

Section II consists of MLI covered with a $1 \mathrm{~mm}$ thick layer of sublimating material that sublimates at a temperature of $950 \mathrm{~K}$. Section III consists of a rigid lid covered with a $4 \mathrm{~mm}$ thick layer of thermal protection material that is radiotransparent.

The MNL was found to be statically and dynamically stable under conditions expected during the descent through the atmosphere from wind tunnel and computer modelling (e.g. see Figs. 14 and 15). An important system attribute of the lander is its stability during flight as this will influence the drag and lift parameters which will in turn affect the uncertainties in predicting its trajectory through the Martian atmosphere.

The drag coefficient of the heat shield, at zero angle of attack, has been determined experimentally (Heilimo et al., 2014) and computed to vary from 1.4 down to 1.0 at 


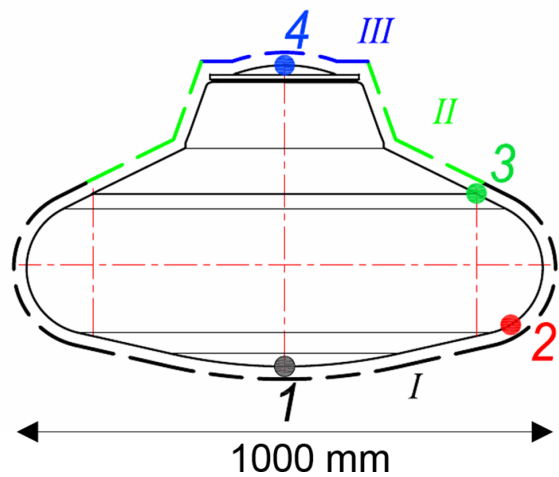

Figure 13. A schematic of MetNet showing the section of the heat protection sections of the inflated aeroshell. Section I covers the rigid frontal structure and inflated torus that supports the outer part of the heat shield. Section II covers the rear of the MNL with section III covering the very back.

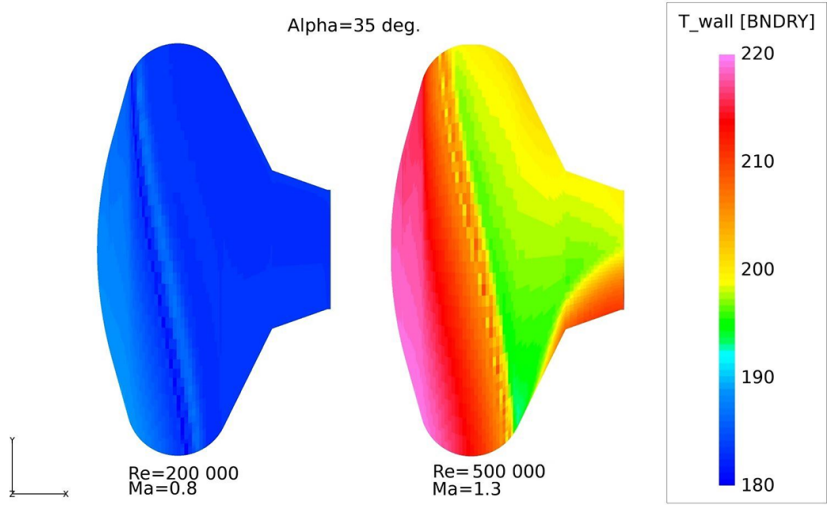

Figure 14. Thermal modelling of the MetNet heat shield according to Finflo Ltd simulations.

Mach 4 and 1 respectively. The drag coefficient with the tension cone deployed after the heat shield has been jettisoned has been determined to vary from 1.1 to 0.9 at Mach 0.8 and Mach 0.2 respectively. The ballistic coefficient controls the impact speed of the penetrator. With the tension cone deployed the ballistic coefficient is between 19 and $22 \mathrm{~kg} \mathrm{~m}^{-2}$.

Trajectory calculations suggest the minimum entry angle for which the lander will not fly back into space is $5.8^{\circ}$. This is assuming a ballistic coefficient of $20 \mathrm{~kg} \mathrm{~m}^{-2}$, an entry altitude of $120 \mathrm{~km}$ and an orbital entry speed of $4586 \mathrm{~m} \mathrm{~s}^{-1}$. Minimum and maximum flight angles suitable for a landing that have been investigated are 9.5 and $13.7^{\circ}$ respectively. It has also been calculated that the flight path angle when the tension cone is deployed will be $60^{\circ}$ and at an altitude of $12 \mathrm{~km}$, assuming the H-IBU has been flying through the atmosphere with zero angle of attack. This will allow ample altitude for the trajectory to turnover and enabling the penetrator to impact the surface vertically. The maximum surface temperature of the rigid TPS surface during the steepest trajectory has been calculated to be $523 \mathrm{~K}$ and a heat flux of
$190 \mathrm{~kW} \mathrm{~m}^{-2}$, which is well below the short-term tolerance of the rigid TPS. See Sect. 3.1.1 for more details on the TPS.

\section{Potential mission types}

\subsection{Overview}

The MNL design features and characteristics both place constraints and open opportunities for implementation mission types and scientific investigations (Table 3 ). This section assesses the design from that point of view and presents some feasible mission types.

As a result of previous flight qualification activities the preparation of a flight-ready spacecraft (vehicle structure and its descent system) is estimated to take 2-4 years. With an entry mass of about $22.2 \mathrm{~kg}$ per unit the MNLs can be easily deployed from a wide range of transfer vehicles. The MNL structure allows the manufacturing of additional MNL units on short notice and at reasonable cost. The entry and descent systems could also be used independently from each other in other lander designs.

Planetary protection requirements are a factor in selection of possible mission types and their landing sites. Being a Mars lander any MNL-based mission is a category IV mission (COSPAR planetary protection policy). A MNL with a non-biological payload falls as a baseline into subcategory IVa with the least stringent sterilisation requirements. Since a MNL's landing involves penetration into the subsurface and depending on the payload complement and the targeted landing area, a MNL mission may also fall in the more stringent subcategories IVb and IVc.

Even if the payload does not include components aimed at studies of Martian extant life, any mission the a Martian special region (for definition and examples see COSPAR planetary protection policy) will have to comply with category IVc requirements. The hard landing also increases the probability of inadvertent exposure of the lander interior with the Martian environment and consequently for any special region mission the entire MNL would have to be sterilised to the Viking post-sterilisation biological burden. Small size of MNL facilitates comprehensive sterilisation of the entire lander.

The MNL decontamination will most likely be performed via a combination of dry heating and hydrogen peroxide treatment. Dry heating is applied for humidity sensor devices.

\subsection{Atmospheric observation networks}

A long-duration (possibly an uninterrupted time series) and global coverage in situ atmospheric science network comprising a truly significant number - from 10-20 to several tens - of observation points on the Martian surface has for a long time been the logical next step for the observational studies of dynamical features of the Martian at- 


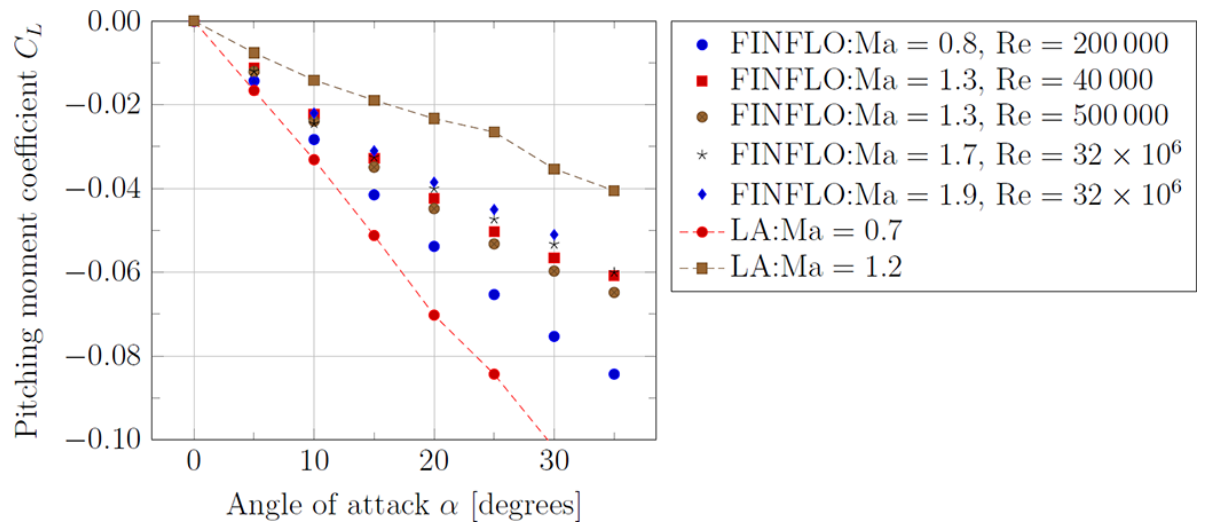

Figure 15. Comparison between the pitching moment coefficients for the heat shield case obtained by numerical simulations using FINFLO numerical code developed by Finflo Ltd and from LA.

Table 3. Key MNL design characteristics along with the associated impact (+/-) and mission design constraints.

\begin{tabular}{|c|c|c|}
\hline Characteristic & Impact & Impact description, constraints \\
\hline Low unit mass & + & $\begin{array}{l}\text { Increased launch opportunities (piggy-backing), de- } \\
\text { ployment of multiple units with single launch }\end{array}$ \\
\hline Low unit mass & + & $\begin{array}{l}\text { Enables the establishment of an investigation consisting } \\
\text { of multiple payloads on the Martian surface }\end{array}$ \\
\hline $\begin{array}{l}\text { Entry from interplanetary } \\
\text { trajectory or parking orbit }\end{array}$ & + & $\begin{array}{l}\text { Adaptability to different mission concepts and landing } \\
\text { accuracy requirements }\end{array}$ \\
\hline High impact acceleration & - & $\begin{array}{l}\text { Only robust instrument concepts feasible, modification } \\
\text { of the subsurface materials adjacent to the lander sur- } \\
\text { face }\end{array}$ \\
\hline $\begin{array}{l}\text { Stable thermal environment } \\
\text { in payload volume }\end{array}$ & + & Reduced instrument thermal control requirements \\
\hline $\begin{array}{l}\text { Stable near-vertical attitude } \\
\text { after landing }\end{array}$ & + & \\
\hline $\begin{array}{l}\text { Limited control over the } \\
\text { post-landing attitude }\end{array}$ & - & \\
\hline Access to subsurface layers & + & $\begin{array}{l}\text { Enables subsurface observations without digging or } \\
\text { drilling }\end{array}$ \\
\hline $\begin{array}{l}\text { Limited electrical power } \\
\text { and power storage }\end{array}$ & - & Limits instrument selection and operations \\
\hline $\begin{array}{l}\text { Both up- and down- } \\
\text { links required }\end{array}$ & - & Constrains feasible mission concepts \\
\hline $\begin{array}{l}\text { Requirements placed on the } \\
\text { carrier spacecraft }\end{array}$ & - & Constrains available carrier and mission concepts \\
\hline $\begin{array}{l}\text { Electromagnetic } \\
\text { cleanliness }\end{array}$ & - & $\begin{array}{l}\text { Constrains feasible instruments and their measurement } \\
\text { accuracy }\end{array}$ \\
\hline Planetary protection & - & $\begin{array}{l}\text { Constrains types of instruments and allowed landing } \\
\text { areas }\end{array}$ \\
\hline
\end{tabular}

mosphere. Several different network concepts - differing in size and complexity of individual landers as well as number of landers forming the network - have been proposed (MESUR study report; Chicarro et al., 1993; Chicarro, 1994; Merrihew et al., 1996; Haberle and Catling, 1996; Linkin et al., 1998; Harri et al., 1999, 2007).

A spatially wide and comprehensive network alone would provide a significant leap in spatial and temporal (from diur- nal to seasonal and up to interannual scales) characterisation of the global circulation patterns and the major climatological cycles of dust, $\mathrm{H}_{2} \mathrm{O}$ and $\mathrm{CO}_{2}$ (Savijärvi et al., 2005; Harri et al., 2014b, a; Savijärvi et al., 2016). The MNL concept offers a cost-effective and hence realistic element and tool for deploying such a network. The potentially large number of observation points combined with careful selection of locations would permit analyses taking into account also corre- 


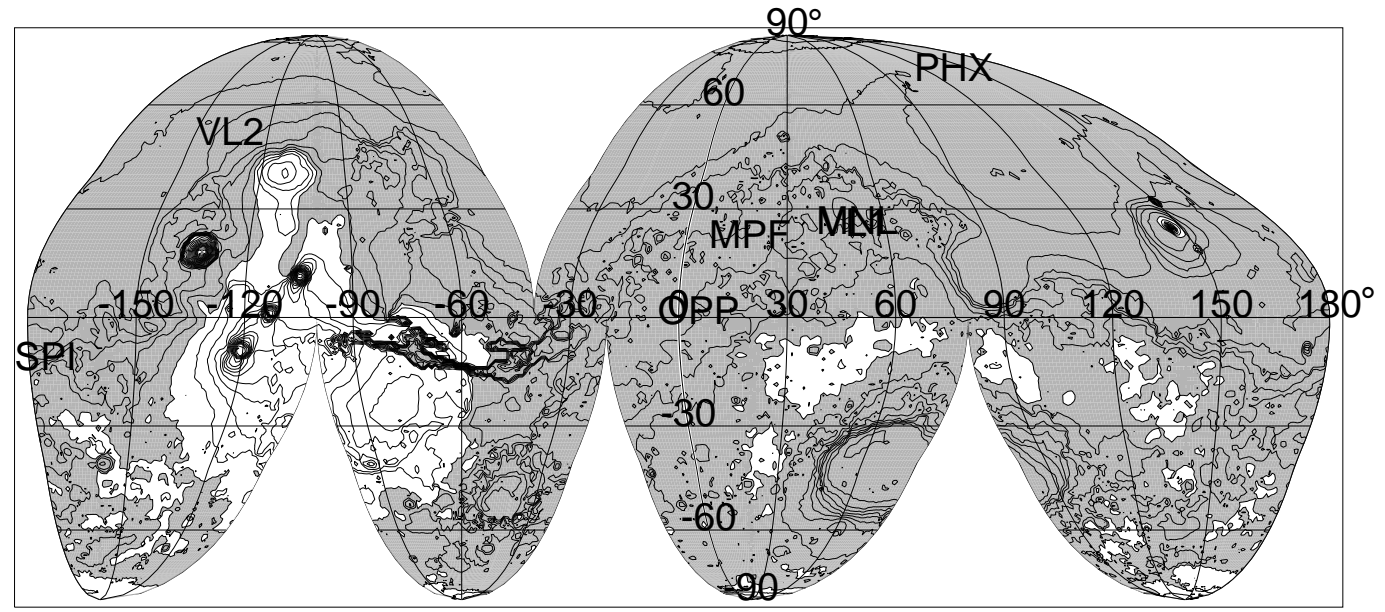

Figure 16. Areas with low enough surface altitudes $(<2 \mathrm{~km}$ above the datum) suitable as MNL landing sites are shown in grey. Shown are also landing areas of Viking Landers (VL1, VL2), Mars Pathfinder (MPF), Opportunity (OPP), Spirit (SPI), Phoenix (PHX), Mars Science Lander and a proposed MNL Precursor mission.

lations between observations. Such a set of observations has also the potential for providing sufficient constraints to become useful for assimilation into and with Mars atmospheric circulation models. Figure 16 shows the constraints on location, in terms of surface altitudes, for the MNL.

Optimal locations of observation posts depend on the total number of the network elements. If a network consists of only a few observation posts, it is worthwhile to either create a small local network or place the posts on different types of terrain and latitudes. This would encompass differences in altitude, latitude and type of surface. In all cases we should place observation posts also on the locations, where observations were previously performed by the Viking Landers (VLs), the Mars Pathfinder or the MSL. This would enable us to compare the current atmosphere at those sites to the atmospheric conditions prevailing earlier. This would be especially interesting at the VL and MSL sites, where longduration observations are available.

Even though the initial emphasis and focus is from atmospheric science point of view naturally in achieving global and long-term coverage, in later stages one can envision deploying clusters of 3-4 landers regionally and with interstation separations of $100-1000 \mathrm{~km}$ to form mesoscale subnetworks (Fig. 17). Such subnetworks would be highly useful in more detailed studies of circulation patterns in regions of particular interest, e.g. the Tharsis volcano area, Valles Marineris, Hellas or perhaps the circumferences and vicinities of the permanent polar caps. The availability of observations would allow for regional models to be tuned to the characteristics of that particular region for provisions of improved understanding of the atmospheric processes and atmospheresurface interactions, leading also to more accurate regional forecasts.

\subsection{Joint rover-MNL atmospheric science missions}

A subnetwork with interstation dimensions similar to a characteristic range of a longer-range rover (tens to a hundred $\mathrm{km}$; the network "bracketing" or "interleaving" the areaof-operation of a rover) offers opportunities for having the MNLs and the rover carrying mutually complementary atmospheric science payloads with intercomparison and intercalibration opportunities. The rover could for instance carry more complex and resource-hungry instruments (e.g. MiniTES or LIDAR type) that the MNLs could not include in their payloads. Such an arrangement would combine in the studied region stationary longer-term time series measurements with mobile, more advanced and spatially "sampling" type observations.

\subsection{Atmospheric observations at high-risk locations}

Although correlated and combined observations are qualitatively a leap forward from previous types of observations, the potentially larger numbers of deployable MNLs and acceptance of higher risk of the failure of a single vehicle (e.g. see Harri et al., 2012, and Lorenz, 2011) would permit clear advantages for studies in microscale meteorology and atmosphere-surface interactions (e.g. momentum and thermal fluxes): MNLs could be deployed to a large number of very different and also riskier locations and terrains, thus allowing for observations in and of terrains otherwise unlikely to be reachable.

\subsection{Dedicated ground truth landers for atmospheric sounders}

For best accuracy, atmospheric in-orbit sounder observations need so-called ground truth - typically independent informa- 


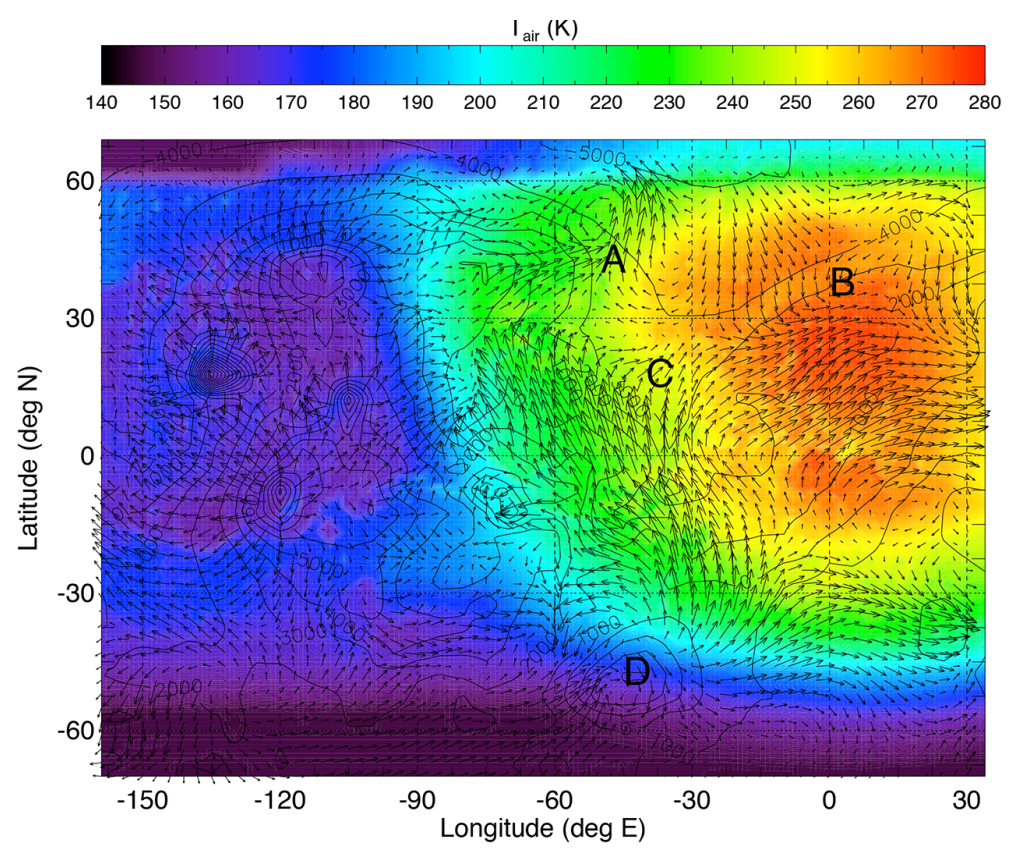

Figure 17. A schematic illustration of a four-lander subnetwork deployed into the equatorial region. The left figure shows the simulated near-surface temperature $\left(T_{\text {air }}\right)$ and wind fields $(\boldsymbol{V})$ along with the labels $(\mathrm{A}-\mathrm{D})$ of four possible landing sites. The data shown have been simulated with the Finnish Meteorological Institute/University of Helsinki Mars Limited Area Model; see e.g. Kauhanen et al., 2008).

tion on, for instance, the surface pressure. This can be provided by model estimates, but in situ observations are most reliable. Hence, having one or more atmospheric sounders in operation simultaneously with surface observation posts - especially a global surface network - would add considerable scientific value: the combination would provide and combine multipoint surface observations (providing ground truth) with spatially and temporally resolved (4-D) remotely sensed atmospheric temperature fields. However, the modest resource requirements of MNLs may enable yet another mission approach or emphasis: an advanced atmospheric remote sounder carrying with it a small number of dedicated wellplaced MNLs for provision of ground truth - perhaps even forming a single mission/launch package.

\subsection{Other science disciplines}

The design offers potential uses in disciplines such as ground studies and seismology. As a MNL lander penetrates the top ground layers, one can envision for instance utilising this in investigations of the top layer of the surface - such as heat fluxes, composition or depth of permafrost. However, one needs to take into account that the energies released in the penetration process very likely modify and ground material immediately adjacent to the penetrator.

\subsection{Pathfinders and precursors for high-value and high-cost missions}

Certain Mars mission classes are inherently of extremely high value - i.e. costly in financial terms, of exceptional scientific value or may place humans at risk. Examples include components of sample return missions, in situ resource utilisation equipment or human missions. Mission assurance is hence of paramount importance and robust ability to observe the weather and atmospheric conditions are important both for planning and execution of the EDLS phase, the lift-off phase as well as surface operations.

The MNL offers an asset and tool for implementing regional weather observation infrastructure to serve high-value missions. The low cost - especially in comparison with the value of the "prime" mission - makes deployment of regional weather observation networks composed of MNLs an approach worthy of consideration. Deployment of such a network could conceivably take place during a launch window preceding a high-value mission, thus allowing for collection of a database of weather observations spanning a full Martian year. Such a data set would in turn provide observational basis for development of verified and tuned regional forecast models for the region and provision of high-fidelity forecasts to serve the prime mission components.

\section{Discussion}

We have developed a Mars lander concept - the MNL - that provides a key landing technology for the future exploration 
Table 4. Comparison of MetNet properties and resources to a range of landers, e.g. Ball et al. (2009). In the fourth column the science payload fraction is the science payload mass divided by the entry mass. The letters $\mathrm{W}, \mathrm{L}$ and $\mathrm{H}$ in the fifth column stand for width, length and height respectively.

\begin{tabular}{lrrrrrrrr}
\hline Lander & $\begin{array}{r}\text { Entry } \\
\text { mass } \\
(\mathrm{kg})\end{array}$ & $\begin{array}{r}\text { Science } \\
\text { payload } \\
\text { mass } \\
(\mathrm{kg})\end{array}$ & $\begin{array}{r}\text { Science } \\
\text { payload } \\
\text { fraction } \\
(\%)\end{array}$ & $\begin{array}{r}\text { Dimensions } \\
\mathrm{W} \times \mathrm{L} \times \mathrm{H} \\
(\mathrm{cm} \times \mathrm{cm} \times \mathrm{cm})\end{array}$ & $\begin{array}{r}\text { Entry } \\
\text { speed } \\
\left(\mathrm{m} \mathrm{s}^{-1}\right)\end{array}$ & $\begin{array}{r}\text { Impact } \\
\text { dece- } \\
\text { leration } \\
(\mathrm{g})\end{array}$ & $\begin{array}{r}\text { Generate } \\
(\mathrm{Wh})\end{array}$ & $\begin{array}{r}\text { Store } \\
(\mathrm{Ah})\end{array}$ \\
\hline MetNet & 22 & 1.5 & 6.8 & $22 \times 22 \times 84$ & 6.0 & 500 & 14.6 & $40(\mathrm{Wh})$ \\
DS2 & 2.73 & 0.15 & 5.5 & $14 \times 14 \times 22$ & 6.9 & $60 \mathrm{k}$ & 0 & 0.6 \\
Pathfinder & 584 & $8+10.5$ & 3.2 & $90 \times 100 \times 100$ & 7.3 & $40(18.6)$ & 1200 & 40 \\
Viking & 992 & 91 & 8.2 & $100 \times 200 \times 50$ & 4.5 & 14 & 1680 & 8 \\
MSL & 2401 & 75 & 3.1 & $270 \times 300 \times 220$ & 5.6 & - & 2640 & 84 \\
\hline
\end{tabular}

of the environment of Mars. By providing a platform for a $4 \mathrm{~kg}$ payload including mechanical structure the MNL is capable of serving various kinds of atmospheric science missions, as well as other kinds of environmental exploration missions

The MNL is a semi-hard penetrator utilising inflatable EDLS structures and mechanisms to improve the landed payload fraction, which is the payload fraction that could conceivably be replaced - for example if a different mission is envisaged using the MNL. The mass of the payload bay with its container and thermal insulation is $4 \mathrm{~kg}$ with an entry mass of $24 \mathrm{~kg}$. Hence a payload fraction of $17 \%$ based on engineering qualification hardware is an excellent number compared to earlier planned Mars landers with similar characteristics (for the Mars-96 penetrators, $F_{\mathrm{pl}}<7 \%$ (Surkov and Kremnev, 1998); for the Deep Space $2 F_{\mathrm{pl}}$ appears not to have been reported in open literature). The design also facilitates thermal control of the payload bay and reduces the number of pyrotechnical devices and commands needed improving the EDLS reliability.

Table 4 compares the MNL to other soft and semi-hard Mars landers and their resources. The science payload fraction is listed here rather than the landed payload fraction. It should be noted that for older spacecraft like the Viking lander the level of integration of the instruments is low, i.e. each instrument may be self-contained rather than sharing resources, with an apparently higher payload ratio for newer spacecraft. Also small landers will tend to have a higher level of integration. The MNL compares favourable in this respect to other types of landers. The small dimensions of the MNL make it small enough to include multiple units in a carrier spacecraft.

The semi-hard nature of the entry, descent and landing system provides an excellent landed payload mass to overall mass ratio of about 0.2 facilitating an efficient use of the mass allocation of a scientific mission. The real strength of the MNL is demonstrated by atmospheric science missions requiring only modest amounts of data bandwidth, electrical energy and mass allocation for their scientific payloads. This facilitates the use of a highly versatile payload within the rel- atively small mass allocation of the MNL vehicle. Furthermore, the MNL EDLS is inherently such that it requires less pyrotechnics (such as explosive bolts) and associated triggering commands than, for example, a traditional parachutebased landing system. This increases the overall likelihood of mission success.

A major asset of the MNL system is the eventual position, where the payload bay and its outer support structures are penetrated under the Martian surface with only the sensor boom, antenna and the outer rim above the surface. Such a position results in a favourable situation, where the payload bay will be surrounded by a natural thermal environment with temperature ranging from $230 \mathrm{~K}$ down to $210 \mathrm{~K}$. These temperatures are still good for the electronics and other parts of the payload with the exception of batteries that need to be protected with additional thermal system. The position underneath the surface is extremely advantageous for a small probe like MNL from a thermal design point of view. At the Martian surface a small payload with low thermal inertia would require heating systems to survive the low night-time temperatures of the order of 170-190 K over a wide range of latitudes. The additional heating system would eat up a large fraction of the payload mass. Hence the MNL concept is giving both thermal shelter and a correct operational position for the payload.

The MNL EDLS allows for deployment to the Martian surface either directly from an interplanetary (hyperbolic) trajectory or from an orbit around Mars. Deployment from orbit enables more accurate landing, whereas direct deployment gives a wider selection of landing sites with the same $\Delta v$ budget. Due to fuel mass savings, direct deployment is often an appealing option - especially for atmospheric science missions for which modest landing precision is often adequate.

Presently two complete MNL EDLS systems have been manufactured and tested. They will be used on the forthcoming MetNet Precursor missions to demonstrate and validate the robustness and efficiency of the design. Prior to the launches parts of the MNL affected by shelf life, such as the fabrics of the inflatable EDLS components, will be replaced 
or refurbished. The Precursor landers will also carry out scientific observations and the development of two sets of atmospheric science payloads is currently under way. The payloads and their observations will be described in a separate paper.

The eventual goal of the MetNet mission concept is to create a network of MNL at the Martian surface operating simultaneously. Eventually a network is needed, for which the MNL is ideally suited. MNL could facilitate the mission with perhaps the launch of 15 units during one launch opportunity.

\subsection{MNL concept validation: Precursor missions}

The eventual validation of the MetNet Lander vehicle concept calls for an actual mission to the Martian surface and operations at Mars. The first concrete steps in this direction have already been taken. Currently an MMPM with one deployed MNL is being planned. The MMPM would perform continuous scientific observations by using a versatile set of science instruments, but the primary objective of this mission is to demonstrate the feasibility and technical robustness of the MNL concept before building the planet-wide network of observational posts.

For the Precursor missions this is extended to include also a three-axis gyroscope device. Additionally a solar incident sensor with a wide range of dedicated wavelength filters, an optical dust sensor, a three-axis magnetometer and a radiation monitor are included in the first units payload.

There exist also plans to deploy a network of some tens of MNLs furbished with atmospheric science instrumentation operating simultaneously and focused on the investigations of the Martian atmosphere. This kind of network mission has been planned for several decades but until now has never been implemented. The MNL concept provides a suitable tool to achieve this long-standing objective.

The eventual scope of the network mission is to operate the multiple scientific payloads at the Martian surface simultaneously for several Martian years. The MNL provides the means to this objective as it is designed to be operational during several Martian years.

A grand goal of creating a network of observational posts at the Martian surface can be reached either by sending a large number of MNLs to Mars onboard a single mission or by sending MNLs to Mars in successive launch windows. The latter network generation scheme requires that the lifetime of MetNet vehicles be of the order of several Martian years.

Individual or stand-alone MetNet missions can make important scientific investigations characterising the Martian environment.

\section{Summary and concluding remarks}

MNL, a small semi-hard lander/penetrator design with a payload mass fraction of approximately $17 \%$, has been devel- oped, tested and prototyped. The MNL features an innovative EDLS that is based on inflatable structures capable of decelerating the lander from interplanetary transfer trajectories down to a surface impact speed of $50-70 \mathrm{~m} \mathrm{~s}^{-1}$ and a deceleration of $<500 \mathrm{~g}$ for $<20 \mathrm{~ms}$. The orientation of the penetrator main body into the surface strata at impact is approximately vertical and since the payload bay will be embedded in the surface materials, the bay's temperature excursions will be much less than if it was fully exposed on the Martian surface. The total mass of the prototype design is $\approx 24 \mathrm{~kg}$, with $\approx 4 \mathrm{~kg}$ of mass available for the payload. The MNL is particularly well suited for delivering meteorological and atmospheric instruments to the Martian surface. The possibility exists for sending other environmental instruments. The small size and low mass of an MNL makes it ideally suited for piggy-backing on larger spacecraft. MNLs are designed primarily for use as surface networks but could also be used as pathfinders for high-value landed missions.

\section{Data availability}

The MetNet Lander concept was developed during several design periods starting as early as 2000 in cooperation with the Lavochkin Association and the Finnish Meteorological Institute. The detailed design documents are not disclosed yet due to contractual constraints.

Competing interests. The authors declare that they have no conflict of interest.

Acknowledgements. The authors would like to express their gratitude to the MetNet development teams at the Finnish Meteorological Institute (Finland), Lavochkin Association (Russia), the Russian Space Research Institute (IKI, Russia) and the Instituto Nacional de Técnica Aeroespacial (INTA, Spain) for their great work in the implementation of the MetNet landing vehicle. Ari-Matti Harri and Hannu Savijarvi are thankful for the Finnish Academy grants no. 132825 and no. 131723.

Edited by: G. Kargl

Reviewed by: R. D. Lorenz and one anonymous referee

\section{References}

Ball, A. J., Garry, J. R. C., Lorenz, R. D., and Kerzhanovich, V. V.: Planetary landers and entry probes, Cambridge University Press, Cambridge, UK, 2009.

Barderas, G. and Romero, P.: On the inverse problem of determining Mars lander coordinates using Phobos eclipse observations, Planet. Space Sci., 79, 39-44, 2013.

CCSDS 211.0-B-4: Proximity-1 Space Link Protocol - Data Link Layer, Consultative Committee for Space Data Systems, CCSDS 
Secretariat, Office of Space Communication (Code M-3), National Aeronautics and Space Administration, Washington, DC 20546, USA, 4 edn., 2006.

Chicarro, A. F., Coradini, M., Fulchignoni, M., Hiller, K., Knudsen, J. M., Liede, I., Lindberg, C., Lognonné, P., Pellinen, R., Spohn, T., Scoon, G. E. N., Taylor, F. W., and Wänke, H.: MARSNET Phase-A Study Report, Tech. Rep. SCI(93)2, European Space Agency, Paris, France, 1993.

Chicarro, A., Scoon, G., and Coradini, M.: INTERMARSNET An international network of stations on Mars for global martian characterisation, ESA Journal, 18, 207-218, 1994.

Clark, I. G., Hutchings, A. L., Tanner, C. L., and Braun, R. D.: Supersonic Inflatable Aerodynamic Decelerators for Use on Future Robotic Missions to Mars, J. Spacecraft Rockets, 46, 340-352, 2009.

COSPAR planetary protection policy: COSPAR planetary protection policy, Policy document, Committee on Space Research (COSPAR), original dated 20 October 2002, amended 24 March 2005, 2005 .

Golombek, M. P., Bridges, N. T., Moore, H. J., Murchie, S. L., Murphy, J. R., Parker, T. J., Rieder, R., Rivellini, T. P., Schofield, J. T., Seiff, A., Singer, R. B., Smith, P. H., Soderblom, L. A., Spencer, D. A., Stoker, C. R., Sullivan, R., Thomas, N., Thurman, S. W., Tomasko, M. G., Vaughan, R. M., Wänke, H., Ward, A. W., and Wilson, G. R.: Overview of the Mars Pathfinder Mission: Launch through landing, surface operations, data sets, and science results, J. Geophys. Res., 104, 8523-8554, 1999.

Gómez-Elvira, J., Armiens, C., Carrasco, I., Genzer, M., Gómez, F., Haberle, R., Hamilton, V. E., Harri, A.-M., Kahanpää, H., Kemppinen, O., Lepinette, A., Martín Soler, J., Martín-Torres, J., Martínez-Frías, J., Mischna, M., Mora, L., Navarro, S., Newman, C., Pablo, M. A., Peinado, V., Polkko, J., Rafkin, S. C. R., Ramos, M., Rennó, N. O., Richardson, M., Rodríguez-Manfredi, J. A., Romeral Planelló, J. J., Sebastián, E., Torre Juárez, M., Torres, J., Urquí, R., Vasavada, A. R., Verdasca, J., and Zorzano, M.P.: Curiosity's rover environmental monitoring station: Overview of the first 100 sols, J. Geophys. Res.-Planet., 119, 1680-1688, doi:10.1002/2013JE004576, 2014.

GOST: Specifications, Tech. rep., 1977.

Grotzinger, J. P., Crisp, J., Vasavada, A. R., Anderson, R. C., Baker, C. J., Barry, R., Blake, D. F., Conrad, P., Edgett, K. S., Ferdowski, B., Gellert, R., Gilbert, J. B., Golombek, M., Gómez-Elvira, J., Hassler, D. M., Jandura, L., Litvak, M., Mahaffy, P., Maki, J., Meyer, M., Malin, M. C., Mitrofanov, I., Simmonds, J. J., Vaniman, D., Welch, R. V., and Wiens, R. C.: Mars Science Laboratory Mission and Science Investigation, Space Sci. Rev., 170, 5-56, doi:10.1007/s11214-012-9892-2, 2012.

Guinn, J. R., Garcia, M. D., and Talley, K.: Mission design of the Phoenix Mars Scout mission, J. Geophys. Res., 113, E00A26, doi:10.1029/2007JE003038, 2008

Haberle, R. M. and Catling, D. C.: A Micro-Meteorological mission for global network science on Mars: rationale and measurement requirements, Planet. Space Sci., 44, 1361-1383, doi:10.1016/S0032-0633(96)00056-6, 1996.

Harri, A., Linkin, V., Polkko, J., Marov, M., Pommereau, J., Lipatov, A., Siili, T., Manuilov, K., Lebedev, V., Lehto, A., Pellinen, R., Pirjola, R., Carpentier, T., Malique, C., Makarov, V., Khloustova, L., Esposito, L., Maki, J., Lawrence, G., and Lystsev, V.: Meteorological observations on Martian surface: met-packages of Mars-96 Small Stations and Penetrators, Planet. Space Sci. 46, 779-793, doi:10.1016/S0032-0633(98)00012-9, 1998.

s Harri, A.-M., Marsal, O., Lognonné, P., Leppelmeier, G. W., Spohn, T., Glassmeier, K.-H., Angrilli, F., Banerdt, W. B., Barriot, J. P., Bertaux, J.-L., Bérthelier, J. J., Calcutt, S., Cerisier, J. C., Crisp, D., Déhant, V., Giardini, D., Jaumann, R., Langevin, Y., Menvielle, M., Mussmann, G., Pommereau, J. P., di Pippo, S., Guerrier, D., Kumpulainen, K., Larsen, S., Mocquet, A., Polkko, J., Runavot, J., Schumacher, W., Siili, T., Simola, J., Tillman, J. E., and the NetLander Team: Network science landers for Mars, Adv. Space Res., 23, 1915-1924, doi:10.1016/S02731177(99)00279-3, 1999.

Harri, A.-M., Leinonen, J., Merikallio, S., Paton, M., Haukka, H., and Polkko, J.: MetNet - In situ observational Network and Orbital platform to investigate the Martian environment, Tech. rep., 2007.

Harri, A.-M., Schmidt, W., Romero, P., Vazquez, L., Barderas, G., Kemppinen, O., A. C., Vazquez-Poletti, J. L., Llorente, I. M., Haukka, H., and Paton, M.: Phobos eclipse detection on Mars: Theory and practice, Tech. rep., 2012.

Harri, A.-M., Genzer, M., Kemppinen, O., Gomez-Elvira, J., Haberle, R., Polkko, J., Savijärvi, H., Rennó, N., RodriguezManfredi, J. A., Schmidt, W., Richardson, M., Siili, T., Paton, M., Torre-Juarez, M. D. L., Mäkinen, T., Newman, C., Rafkin, S., Mischna, M., Merikallio, S., Haukka, H., Martin-Torres, J., Komu, M., Zorzano, M.-P., Peinado, V., Vazquez, L., and Urqui, R.: Mars Science Laboratory relative humidity observations: Initial results, J. Geophys. Res.-Planet., 119, 2132-2147, doi:10.1002/2013JE004514, 2014a.

Harri, A.-M., Genzer, M., Kemppinen, O., Kahanpää, H., GomezElvira, J., Rodriguez-Manfredi, J. A., Habserle, R., Polkko, J., Schmidt, W., Savijärvi, H., Kauhanen, J., Atlaskin, E., Richardson, M., Siili, T., Paton, M., Torre Juarez, M., Newman, C., Rafkin, S., Lemmon, M. T., Mischna, M., Merikallio, S., Haukka, H., Martin-Torres, J., Zorzano, M.-P., Peinado, V., Urqui, R., Lapinette, A., Scodary, A., Mäkinen, T., Vazquez, L., Rennó, N., and REMS/MSL Science Team: Pressure observations by the $\mathrm{Cu}-$ riosity rover: Initial results, J. Geophys. Res.-Planet., 119, 82-92, doi:10.1002/2013JE004423, 2014b.

Heilimo, J., Harri, A.-M., Aleksashkin, S., Koryanov, V., Arruego, I., Schmidt, W., Haukka, H., Finchenko, V., Martynov, M., Ostresko, B., Ponomarenko, A., Kazakovtsev, V., Martin, S., and Siili, T.: RITD - Adapting Mars Entry, Descent and Landing System for Earth, in: EGU General Assembly Conference Abstracts, vol. 16 of EGU General Assembly Conference Abstracts, 2014.

Kauhanen, J., Siili, T., Järvenoja, S., and Savijärvi, H.: The Mars Limited Area Model (MLAM) and simulations of atmospheric circulations for the Phoenix landing area and season-of-operation, J. Geophys. Res., 113, E00A14, doi:10.1029/2007JE003011, 2008.

Linkin, V., Harri, A.-M., Lipatov, A., Belostotskaja, K., Derbunovich, B., Ekonomov, A., Khloustova, L., Kremnev, R. Makarov, V., Martinov, B., Nenarokov, D., Prostov, M., Pustovalov, A., Shustko, G., Järvinen, I., Kivilinna, H., Korpela, S., Kumpulainen, K., Lehto, A., Pellinen, R., Pirjola, R., Riihelä, P., Salminen, A., Schmidt, W., Siili, T., Blamont, J., Carpentier, T., Debus, A., Hua, C. T., Karczewski, J.-F., Laplace, H., Levacher, P., Lognonné, P., Malique, C., Menvielle, M., Mouli, G., Pommereau, J.-P., Quotb, K., Runavot, J., Vienne, D., Grunthaner, F., 
Kuhnke, F., Mussmann, G., Rieder, R., Wänke, H., Economou, T., Herring, M., Lane, A., and McKay, C. P.: A sophisticated lander for scientific exploration of Mars: scientific objectives and implementation of the Mars-96 Small Station, Planet. Space Sci., 46, 717-737, doi:10.1016/S0032-0633(98)00008-7, 1998.

Lorenz, R. D.: Planetary penetrators: Their origins, history and future, Adv. Space Res., 48, 403-431, 2011.

Merrihew, S. C., Haberle, R. M., and Lemke, L. G.: A MicroMeteorological mission for global network science on Mars: a conceptual design, Planet. Space Sci., 44, 1385-1393, doi:10.1016/S0032-0633(96)00055-4, 1996.

MESUR study report: Mars Environmental Survey (MESUR) science objectives and mission description., NASA Ames Rsesearch Center study report, 1991.

Paton, M. D., Harri, A.-M., Savijärvi, H., Mäkinen, T., Hagermann, A., Kemppinen, O., and Johnston, A.: Thermal and microstructural properties of fine-grained material at the Viking Lander 1 site, Icarus, 271, 360-374, doi:10.1016/j.icarus.2016.02.012, 2016.

Romero, P., Barderas, G., Vazquez-Poletti, J. L., and Llorente, I. M.: Spatial chronogram to detect Phobos eclipses on Mars with the MetNet Precursor Lander, Planet. Space Sci., 59, 1542-1550, 2011.

Savijärvi, H., Crisp, D., and Harri, A.-M.: Effects of $\mathrm{CO}_{2}$ and dust on present-day solar radiation and climate on Mars, Q. J. Roy. Meteor. Soc., 131, 2907-2922, doi:10.1256/qj.04.09, 2005.

Savijärvi, H., Harri, A.-M., and Kemppinen, O.: The diurnal water cycle at Curiosity: Role of exchange with the regolith, Icarus, 265, 63-69, doi:10.1016/j.icarus.2015.10.008, 2016.

Shalin, R. E.: Polymer Matrix Composites, Tech. rep., 1995.
Smith, P. H., Tamppari, L., Arvidson, R. E., Bass, D., Blaney, D., Boynton, W., Carswell, A., Catling, D., Clark, B., Duck, T., DeJong, E., Fisher, D., Goetz, W., Gunnlaugsson, P., Hecht, M., Hipkin, V., Hoffman, J., Hviid, S., Keller, H., Kounaves, S., Lange, C. F., Lemmon, M., Madsen, M., Malin, M., Markiewicz, W., Marshall, J., McKay, C., Mellon, M., Michelangeli, D., Ming, D., Morris, R., Renno, N., Pike, W. T., Staufer, U., Stoker, C., Taylor, P., Whiteway, J., Young, S., and Zent, A.: Introduction to special section on the Phoenix Mission: Landing Site Characterization Experiments, Mission Overviews, and Expected Science, J. Geophys. Res.-Planet., 113, E00A18, doi:10.1029/2008JE003083, 2008.

Smrekar, S., Catling, D., Lorenz, R., Magalhães, J., Moersch, J., Morgan, P., Murray, B., Presley, M., Yen, A., Zent, A., and Blaney, D.: Deep Space 2: the Mars microprobe mission, J. Geophys. Res., 104, 27013-27030, doi:10.1029/1999JE001073, 1999.

Soffen, G. A.: Scientific Results of the Viking Missions, Science, 194, 1274-1276, doi:10.1126/science.194.4271.1274, 1976.

Soffen, G. A. and Snyder, C. W.: The First Viking Mission to Mars, Science, 193, 759-766, doi:10.1126/science.193.4255.759, 1976.

Surkov, Y. A. and Kremnev, R. S.: Mars-96 mission: Mars exploration with the use of penetrators, Planet. Space Sci., 46, 1689 1696, doi:10.1016/S0032-0633(98)00071-3, 1998.

Taylor, P. A., Catling, D. C., Daly, M., Dickinson, C. S., Gunnlaugsson, H. P., Harri, A.-M., and Lange, C. F.: Temperature, pressure, and wind instrumentation in the Phoenix meteorological package, J. Geophys. Res.-Planet., 113, E00A10, doi:10.1029/2007JE003015, 2008. 